\title{
STATUS REPORT: \\ MIRROR HYBRID REACTOR STUDIES
}
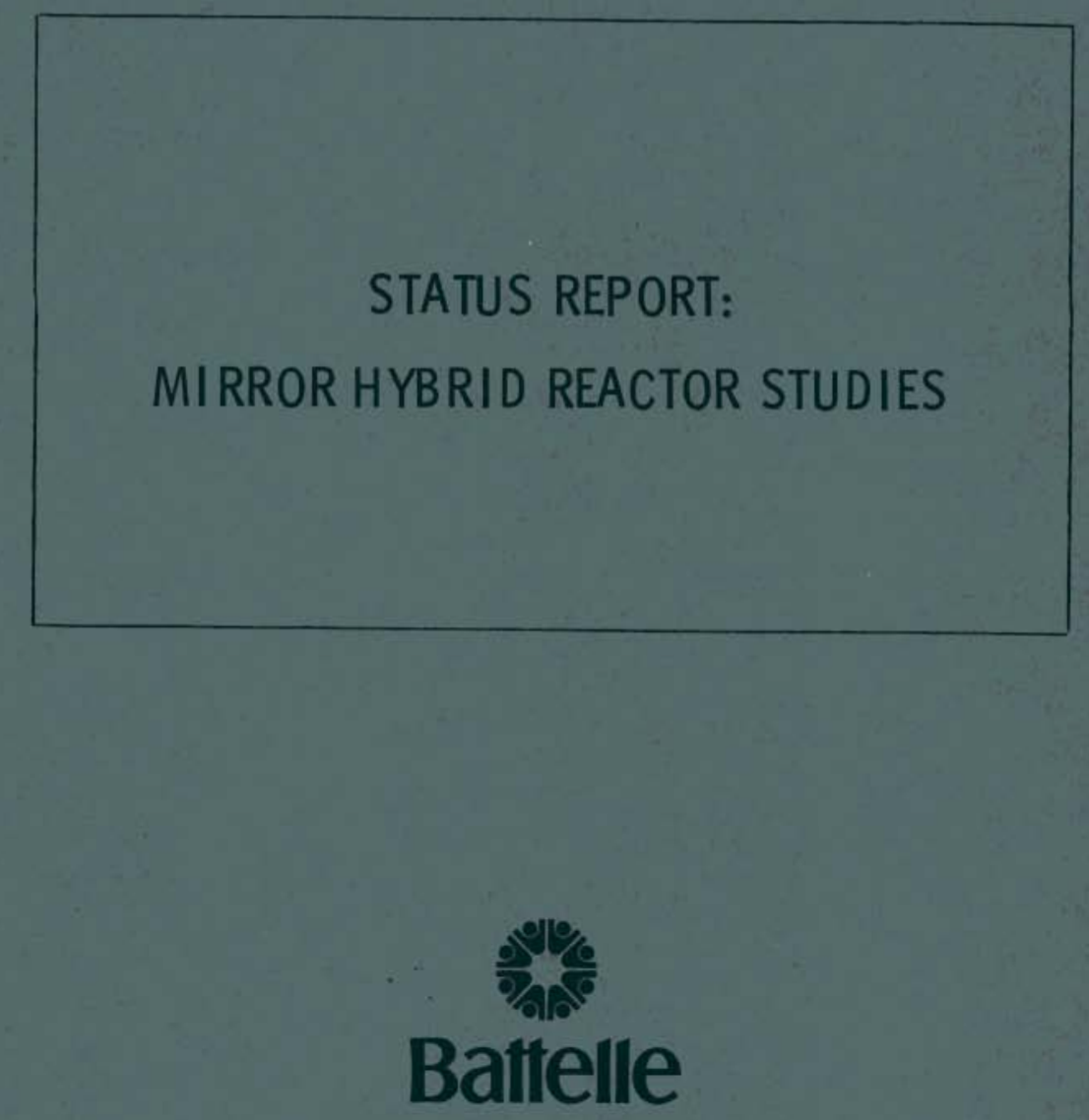

Pacific Northwest Laboratories

Richland, Washington 99352

NOVEMBER 1974

Prepared for the U.S. Atomic Energy

Commission under Contract AT(45-1):1830 
NOTICE

This report was prepared as an account of work sponsored by the United States Government. Neither the United States nor the United States Atomic Energy Commission, nor any of their employees, nor any of their contractors, subcontractors, or thier employees, makes any warranty, express or implied, or assumes any legal liability or responsibility for the accuracy, completeness or usefulness of any information, apparatus, product or process disclosed, or represents that its use would not infringe privately owned rights.

PACIFIC NORTHWEST LABORATORY

operated by

BATTELLE

for the

U.S. ATOMIC ENERGY COMMISSION

Under Contract AT(45-1)-1830

\author{
Printed in the United States of America \\ Available from \\ National Technical Information Service \\ U.S. Department of Commerce \\ 5285 Port Royal Road \\ Springfield, Virginia 22151 \\ Price: Printed Copy \$7.60: Microfische \$2.25
}


BNWL -1835

UC -20

Special Distribution

\author{
STATUS REPORT: \\ MIRROR HYBRID REACTOR STUDIES
}

Contributing Authors

W. C. Wolkenhauer

B. R. Leonard, Jr.

$U$. P. Jenquin

D. F. Newman

A. M. Sutey

C. W. Stewart

D. L. Prezbindowski

R. W. Moir

J. D. Lee

R. W. Werner - LLL

Technical Editors

Elizabeth Stokes

Elizabeth Reppond

November 1974

PACIFIC NORTHWEST LABORATORIES

RICHLAND, WASHINGTON 99352

Prepared for the U. S. Atomic Energy

Commission under Contract AT(45-1): 1830 


\section{TABLE OF CONTENTS}

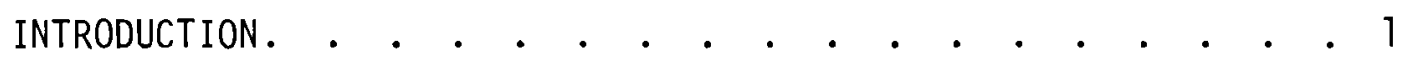

STUDY GUIDELINES AND TECHNICAL APPROACH. . . . . . . . . . 2 SUMMARY AND CONCLUSIONS . . . . . . . . . . . . . . . 3

I. MIRROR FUSION REACTOR DESIGN

I I. BLANKET DESIGN . . . . . . . . . . . . . . . 15

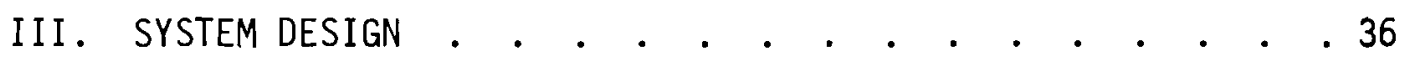

IV. RADIOACTIVE MATERIAL INVENTORY. . . . . . . . . . . 41

V. AREAS OF FUTURE DEVELOPMENT. . . . . . . . . . . . . . 47

REFERENCES . . . . . . . . . . . . . . . . . . . 49

APPENDIX A . . . . . . . . . . . . . . . . . . . . . .

APPENDIX B . . . . . . . . . . . . . . . . . . . . . . .

APPENDIX C . . . . . . . . . . . . . . . . . $C_{-1}$

APPENDIX D . . . . . . . . . . . . . . . . . . . . .

DISTRIBUTION. . . . . . . . . . . . . . . . . . . . . . . . . . . . . . 


\section{LIST OF FIGURES}

1.1 Mirror Hybrid Reactor. . . . . . . . . . . . 10

1.2 Preliminary Magnet Design . . . . . . . . . . . . 11

2.1 Hybrid Blanket Module. . . . . . . . . . . . 16

2.2 Neutron Balance Versus Fuel Pin Pitch . . . . . . . 22

2.3 Initial Conversion Ratio (ICR) Versus Fuel Pin Pitch . . 22

2.4 Blanket Nodalization . . . . . . . . . . 30

2.5 Effect of Power on Temperatures with Constant-Coolant Temperature Rise . . . . . . . . . . . . . 31

2.6 Steady State Temperature Distribution . . . . . . . 31

2.7 Comparison of Power Profiles . . . . . . . . . . 33

2.8 Effect of Power Distribution on Lattice Temperatures . . 33

2.9 LOCA Transient Temperatures. . . . . . . . . . . 35

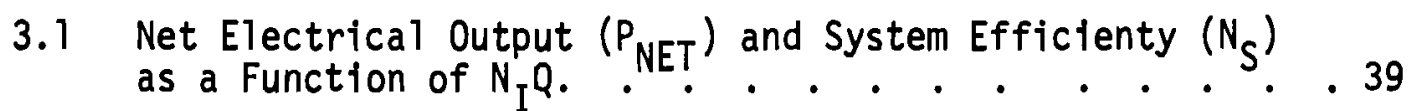

3.2 System Efficiency $\left(N_{S}\right)$ as a Function of Injector Efficiency $\left(\mathrm{N}_{\mathrm{I}}\right)$ and Q. . . . . . . . . . . . 39

4.1 Radioactive Afterheat of Mirror Hybrid Reactor . . . . 45

B.1 Distribution of ${ }^{63} \mathrm{Cu}(n, 2 n)$ Reaction . . . . . . . B-5

B.2 Distribution of $238 U$ fission Rate. . . . . . . . B-6

B.3 Distribution of $238 \mathrm{U}$ Neutron Capture Rate . . . . . .B-6

B.4 Distribution of $235 \mathrm{U}$ Fission Rate. . . . . . . . . B-7

B.5 Distribution of ${ }^{239 P u ~ F i s s t o n ~ R a t e ~ . ~ . ~ . ~ . ~ . ~ . ~ . ~ B-7 ~}$

C.1 Mirror Hybrid Schematic Diagram . . . . . . . .C-1 


\section{LIST OF TABLES}

1.1 Design Parameters of the LLL/PNL Mirror Hybrid Reactor. 7

2.1 Summary of Candidate Blanket Geometries. . . . . . 17

2.2 Lattice Particle Fuel Design . . . • . . • . . . 19

2.3 Mirror Hybrid Composite Blanket Analysis . . . . . . 27

3.1 Current Hybrid Reactor Design Parameters . . . . . . 39

4.1 Radioactive Inventory of Mirror Hybrid Reactor . . . . 43

A.1 Transfer of Data from EGGNIT/GRANIT to 27 Energy Group Format. . . . . . . . . . . . . . . . .A-3

B.1 Group Structure Used for ANISN Calculations . . . . . B-4

D. 1 Geometric Buckling Expressions for Fusion Reactor Blankets . . . . . . . . . . . . . . . . D-4 
BNWL-1835

INTRODUCTION

A key element in this nation's developing energy economy is the effective utilization of nuclear power. In the near term (early in the 2000 's) considerable reliance is being placed upon fission reactors for producing electric power. In the long term, the hope is to develop the Controlled Thermonuclear Reactor (CTR), (i.e. fusion reactor) as a viable producer of electric power.

A concept which involves elements of both fission and fusion technologies is the fusion-fission hybrid reactor. (1) This type of reactor might very well play a useful role in the scenario of exploitation of fission power and the development of fusion power to commercial scale. The hybrid reactor could possibly be developed sooner than CTRs on the basis of less stringent plasma requirements. Alternatively, it appears possible that the hybrid reactor could extend the supply of resources for fission reactors by producing fissionable materials such as $233 \mathrm{U}$ or plutonium. It also might be applicable for reduction of waste produced in fission power reactors.

The concept of fusion-fission hybrid systems involves the coupling of the energetic neutrons from fusion reactions with fissile or fertile nuclei to produce a multiplication of the fusion neutron source strength and, ultimately, the production of energy from nuclear fission. As mentioned above, there appears to be two distinct classes of hybrid reactors. The first of these is a reactor which serves as an adjunct to fission reactors by producing fissionable materials or reducing fission reactor waste. The second class is a self-contained electrical power plant which is the focus of this study.

A study was undertaken to make a preliminary assessment of the engineering characteristics of a hybrid reactor. A cooperative effort was established between Pacific Northwest Laboratory (PNL) and Lawrence Livermore Laboratory (LLL) to develop a scope design for a hybrid reactor based on the mirror fusion reactor concept. Though the mirror fusion device is one of many candidates for the fusion segment of the hybrid, it 
represents a good candidate for making a preliminary assessment of hybrid characteristics because the mirror fusion reactor has some apparent geometrical advantages with regard to hybrid design. This document is a status report of this scope design study.

\section{STUDY GUIDELINES AND TECHNICAL APPROACH}

In general, the underlying guideline for the study was to employ wherever possible current technology for the fission and mirror fusion segments of the hybrid. The basic design objectives were to:

(1) produce electrical power

(2) produce as much tritium as consumed

and (3) produce more fissionable material than consumed within the safety criterion of maintaining the reactor subcritical at all times.

Since currently available technology was used, certain design analyses were assumed as already completed, thus narrowing the calculational effort. Calculations were made to define the plasma characteristics and these were used as starting points for evaluating the neutronic, thermal, and fluid flow characteristics of the fission blanket. The study being a scope design, led to choosing a calculational approach based upon survey methods rather than rigorous and detailed analysis methods. A description of the calculational methods used in the study are given in Appendix A. In order to provide some confidence in the relative degree of accuracy of the calculational methods, comparisons between calculated and measured $14 \mathrm{MeV}$ neutron reaction rates were made. The results of these studies gave a measure of confidence to the results obtained in the scope design and these results are reported in Appendix B. 


\section{SUMMARY AND CONCLUSIONS}

A scope design effort for a mirror hybrid reactor was undertaken to estimate the performance characteristics of this type of fission-fusion system. The basic blanket is a composite convertor/fissile lattice configuration which is based upon previous work at PNL. (2) The fissile lattice materials and arrangement were selected as representative of gas cooled thermal reactor technology. The scope design included analysis of plasma physics characteristics, blanket neutronic and thermal hydraulic characteristics, magnet design considerations, and injector design. A basic aim of the study was to provide bases for understanding the shortcomings and advantages of hybrids.

For perspective, an artist's conception of the mirror hybrid reactor is shown in Figure 1.1. Some details of the blanket design are shown in Figure 2.1. Values arrived at in this study for the major design parameters of the mirror hybrid are listed in Table 1.1. In summary, this design:

- produces $660 \mathrm{MW}$ of electricity

- produces as much tritium as consumed and more fissionable material than consumed

- is always subcritical (i.e., k kff less than 1.0)

A concern in design of fission reactors is an accident whereby coolant is lost and fuel melting occurs. In this study, an analysis was made of the consequence of loss of coolant in the fission blanket. The results indicate that fuel melting is not expected to occur if coolant is lost.

In general, the guidelines for application of existing technology were met.

As stated previously, a guideline for the study was to use current technology. In the course of the study, it became apparent that certain aspects of the design require advances in technology. The major exceptions were extrapolations from current plasma technology, and in blanket design technology for gas cooled fission lattices. Research and 
development efforts are required to advance the technology and achieve design safety margins which are as large as possible while concurrently achieving high energy multiplication and more power output.

Areas which should receive more attention in future work on mirror hybrids are outlined in Section $V$ of this report.

A number of conclusions have been reached with regard to mirror hybrids as a result of this study and other related reports. $(2,3)$

- A sub-Lawson mirror hybrid reactor with a subcritical fission blanket based on Gas Cooled Reactor technology appears possible.

- The geometry of a mirror fusion reactor allows for acceptable access to the fissile blanket while allowing for acceptable neutron leakage rates.

- Fissile and tritium breeding can be attained in a hybrid with large energy multiplication.

- The mirror hybrid can be designed not to experience a reactivity insertion accident.

- The mirror hybrid design is not expected to experience fuel meltdown as a consequence of a loss-of-coolant accident.

Some of the characteristics of the mirror hybrid reactor in particular and hybrid reactors in general have become apparent in this and other work already accomplished. (4) These general characteristics, as they compare to fission and fusion reactors are summarized below.

\section{Favorable Characteristics}

Fusion Reactor

- Sub-Lawson plasma

- Reduced materials radiation damage

- High power density

- Reduced tritium inventory 


\section{Fission Reactor}

- Sub-critical fissile array, therefore does not require reactivity control

- Meltdown following loss of coolant less probable

- Smaller actinide waste fraction

- Improved fissile material production rate

- Lower inventory of radioactive material

Unfavorable Characteristics

Fusion Reactor

- Higher inventory of radioactive material

Fission Reactor

- Handling and storage of large amounts of tritium 


\section{MIRROR FUSION REACTOR DESIGN}

Design of the mirror hybrid reactor is initiated with design and preliminary specification of the mirror fusion reactor. The starting point for the design is the Lawrence Livermore Laboratory (LLL) "Austin Conference Design". (5) This reactor is modified and adapted to the needs of the mirror hybrid design. Table 1.1 gives the design parameters of the LLL/PNL mirror hybrid reactor.

\section{A. PLASMA PHYSICS PARAMETERS AND MAGNET DESIGN}

The fusion power $\left(P_{F U S}\right)$ for the mirror fusion reactor employed in this hybrid design can be expressed as:

$$
P_{F U S}=\frac{n_{\infty}^{2}}{4}(\overline{\sigma V})_{D T} E_{f} A C_{\pi} R^{2} L
$$

where

$$
\begin{aligned}
n_{\infty}= & \text { the ion density at the center of the plasma. } \\
(\overline{\sigma V})_{D T}= & \text { the reaction rate for the deuterium-tritium (D-T) fusion } \\
& \text { reaction averaged over the ion velocity distribution. } \\
E_{f}= & \text { the fusion energy release per reaction }(17.58 \mathrm{MeV}) . \\
A \quad= & \text { a parameter which accounts for the nonuniform radial power } \\
& \text { production. } \\
L \quad= & \text { the distance from mirror point to mirror point. } \\
R \quad= & \text { plasma radius. } \\
C \quad= & \text { a parameter which accounts for both decrease in the plasma } \\
& \text { cross-section area proportional to the reciprocal of the } \\
& \text { magnetic field and for axial nonuniformity of power. }
\end{aligned}
$$

In the plasma physics design, we assume $n$ to vary radially as $1-(r / R)^{3}$ at the midplane where the plasma is approximately circular. The injection energy for deuterium ions is taken as $120 \mathrm{keV}$ and for tritium 


\section{TABLE 1.1 Design Parameters of the LLL/PNL Mirror Hybrid Reactor}

PLASMA

Shape
Type
Volume
Mean Radius
Mean Energy
INWECTOR

Injected Power

Ave. Injection Energy

Injection Current

Injector Area Required

Type

No. Injectors

MAGNET COIL

Radius
Width
Height
Central Vacuum Field
Mirror Field

Mirror Field

Field at Conductor

POWER DISTRIBUTION

$\begin{array}{ll}P_{\text {Fusion }} & 64.2 \mathrm{MWt} \\ P_{\text {injection }} & 68.3 \mathrm{MNe} \\ P_{\text {net }} & 663.8 \text { Mile } \\ \text { System Efficiency } & 32 \%\end{array}$

BLANKET

Neutronics

$\begin{array}{ll}\text { Energy Multiplication Factor } & 39.8 \\ \text { Tritium Breeding Ratio } & 1.0 \\ \text { Fissile Breeding Ratio } & 11 \\ \text { Uranium Inventory } & 183 \mathrm{MT}\left(\mathrm{UO}_{2}\right) \\ \text { Tritium Inventory } & =0.7 \mathrm{~kg} \\ \text { Lithium Inventory } & 10.5 \mathrm{MT} \\ \left.\text { Effective Multiplication ( } \mathrm{k}_{\mathrm{eff}}\right) & .88\end{array}$

Neutron Convertor (Initial 81 anket Region)

Clad

Fuel Enrichment

Fuel Form

Total Loading

Thickness
Ellipsoid (near spherical)
Deuterium-Tritium
$3.8 \times 10^{2} \mathrm{~m}^{3}$
$3.5 \mathrm{~m}$
$150 \mathrm{kev}$

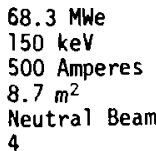

$210 \mathrm{~m}$

$6.5 \mathrm{~m}$
$4.0 \mathrm{~m}$

$1.93 \mathrm{~T}$

$7.1 \mathrm{~T}$

$8.4 \mathrm{~T}$

64.2 Mint

663.8 whe

$.254 \mathrm{~cm}$ stainless steel Natural or Depleted Uranium $\mathrm{UO}_{2}$ plates

$124 \mathrm{MT}\left(\mathrm{UO}_{2}\right)$

$8.5 \mathrm{~cm}$
Lattice (Second Blanket Region)

\begin{tabular}{|c|c|}
\hline $\begin{array}{l}\text { Pitch } \\
\text { Thickness } \\
\text { Fuel Column Diameter } \\
\text { Coolant Channel Diameter } \\
\text { Fuel Enrichment } \\
\text { Fuel Form } \\
\text { Particle Kernel } \\
\text { Coating }\end{array}$ & $\begin{array}{l}3.81 \mathrm{~cm} \text { triangular } \\
180 \mathrm{~cm} \\
1.27 \mathrm{~cm} \\
1.65 \mathrm{~cm} \\
1.35 \% \mathrm{Fissile}(235 \mathrm{U}) \\
60_{2} \\
1000 \mu \mathrm{m} \\
\mathrm{C}_{\text {L.D }}, \mathrm{C}_{H . D}, \mathrm{SiC}, \mathrm{C}_{H . D}\end{array}$ \\
\hline $\begin{array}{l}\text { Total Loading } \\
\text { Carbon/Uranium ratio }(\mathrm{C} / \mathrm{U})\end{array}$ & $\begin{array}{l}58.9 \mathrm{MT}\left(\mathrm{UO}_{2}\right) \\
170\end{array}$ \\
\hline $\begin{array}{l}\text { Migration Area }\left(\mathrm{M}^{2}\right) \\
238_{\text {U Resonance Integral }}(\mathrm{RI}) \\
\text { Packing Fraction }\end{array}$ & $\begin{array}{l}=560 \mathrm{~cm}^{2} \\
=35 \text { barns } \\
0.60\end{array}$ \\
\hline $\begin{array}{l}\text { Ratio of Fuel Columns/ } \\
\text { Coolant Holes }\end{array}$ & $2: 1$ \\
\hline $\begin{array}{l}\text { Doppler Coefficient } \\
\text { Power Density }\end{array}$ & $\begin{array}{l}-2.1 \times 10^{-3} /{ }^{\circ} \mathrm{K}^{1 / 2} \\
4.3 \mathrm{~W} / \mathrm{cm}^{3}\end{array}$ \\
\hline${ }^{*} C_{L . D}=>$ Low density carbon; & \\
\hline$C_{H, D} \Rightarrow$ sigh density carbon. & \\
\hline
\end{tabular}

GEOMETRY

Geodesic; 320 modules

SHIELD

Thickness

1 meter, composition unspecified but predominantly stainless stee?

THERMAL HYORAULICS

Coolant

Channel Heat Flux

Coolant Pressure

Coolant Flow Rate

Total Blanket Power

Coolant Heat Transfer Area

Moderator Temperature

Fuel Temperature

Inlet Temperature
Hel ium

$32 \mathrm{~W} / \mathrm{cm}^{2}$

$20.4 \mathrm{Atm}$. $0.367 \times 10^{4} \mathrm{~kg} / \mathrm{sec}$

2045.4 MWt

$3800 \mathrm{~m}^{2}$

$732^{\circ} \mathrm{C}$

$1500^{\circ} \mathrm{C}$

$404^{\circ} \mathrm{C}$

$816^{\circ} \mathrm{C}$ 
ions as $180 \mathrm{keV}$, which we will justify later. A 50-50 mixture results in a mean injection energy of $150 \mathrm{keV}$. This value sets the reaction rate parameter, defined above, at $8.6 \times 10^{-16} \mathrm{~cm}^{3} \mathrm{sec}^{-1}$.

For a flat power profile, A equals 1 . For the cubic profile used here, $A=9 / 20$. Using $L$ as length, and $R$ as radius, $\pi R^{2} L$ is the volume of a right circular cylinder. Here we are using $2000 \mathrm{~cm}$ as the distance between mirror points and the plasma radius as $350 \mathrm{~cm}$.

The plasma cross-section area decreases with the reciprocal of the magnetic field $\left(B^{-1}\right)$ toward the mirrors. Additionally, the power is nonuniform in the axial direction. Both of these factors are accounted for in the parameter $C$. The value of $C$ lised is 0.214 . Further details of the analysis and derivation of $A$ and $C$ are found in Reference 6.

If these values are inserted into Equation 1.1 with conversion of power in megawatts, the resultant relationship is:

$$
P_{F U S}=n_{\infty}^{2} 4.48 \times 10^{-26} \mathrm{MW}
$$

As developed later in Section III, $P_{\text {FUS }}$ is selected to be $64.2 \mathrm{MW}$. Thus, Equation 1.2 yields a central ion density of $3.8 \times 10^{13}$ ions $/ \mathrm{cm}^{3}$. These parameters constitute the major plasma physics parameters of the design.

The magnetic field strength required to confine the above defined plasma in a configuration which is stable from a magnetohydrodynamic point of view is obtained from an equation relating the plasma pressure to the magnetic field pressure. This relationship is:

$$
\beta=\frac{P_{\perp}}{\frac{B_{\text {vac }}^{2}}{2 \mu_{0}}}=\frac{n_{D} \bar{W}_{D} \frac{2}{3} \gamma+n_{T} \bar{W}_{T} \frac{2}{3} \gamma+n_{e} \bar{W}_{e} \frac{2}{3}+n_{H e} \bar{W}_{H e \frac{2}{3}} \gamma}{\frac{B_{v a c}^{2}}{2 \mu_{0}}}
$$


BNWL - 1835

where

$\beta$ is defined as the ratio of the perpendicular plasma pressure to the magnetic field pressure.

$\gamma=$ a parameter which accounts for the presence of more energy perpendicular to the magnetic field than would be the case in an isotropic veiocity distribution. The value of $\gamma$ is taken here to be $1.3^{(7)}$

B = the magnetic field at the center of the device.

$B_{\text {vac }} \quad=B$, with no plasma present.

$n_{D}, n_{T}, n_{e}, n_{H e}=$ density of deuteron, triton, electrons, helium ions

$\bar{W}_{D}, \bar{W}_{T}, \bar{W}_{e}, \bar{W}_{\mathrm{He}}=\underset{\text { mean energy of deuteron, triton, electrons, helium }}{\text { ions }}$.

An estimate based on Fokker-Planck calculations under similar conditions indicates that the energies of the ions are: $\bar{W}_{D}=140 \mathrm{keV}, \bar{W}_{T}=180 \mathrm{keV}$, $\bar{W}_{\mathrm{e}}=29 \mathrm{keV}$, and $\bar{W}_{\mathrm{He}}=320 \mathrm{keV}$. The ratio of helium ion density to the fuel ion density is 0.01 based on these calculations.

Stability theory indicates $(7)$ for a mirror ratio $\left(B_{\max } / B_{\min }\right)$ of 7 and injection perpendicular to $B$ that $\beta$ can be 0.65 . If the above parameters and this value of $\beta$ are substituted into Equation 1.3, one finds that the required central vacuum field strength is 1.93 tesla ( $T$ ). The plasma tends to reduce the magnetic field because it is diamagnetic. The reduction goes approximately as $\sqrt{1-\beta}$. For a value of $\beta=0.65$, the central magnetic field with the plasma present is then $1.06 \mathrm{~T}$.

The mirror fusion reactor design is shown in Figure 1.1. The preliminary magnet design and plasma shape are shown in Figure 1.2. The mirror magnetic field for the magnet shown in Figure 1.2 is $7.1 \mathrm{~T}$, giving a vacuum mirror ratio of 3.6 and a plasma mirror ratio of 6.57 . The peak magnetic field at the conductor is $8.4 \mathrm{~T}$. 


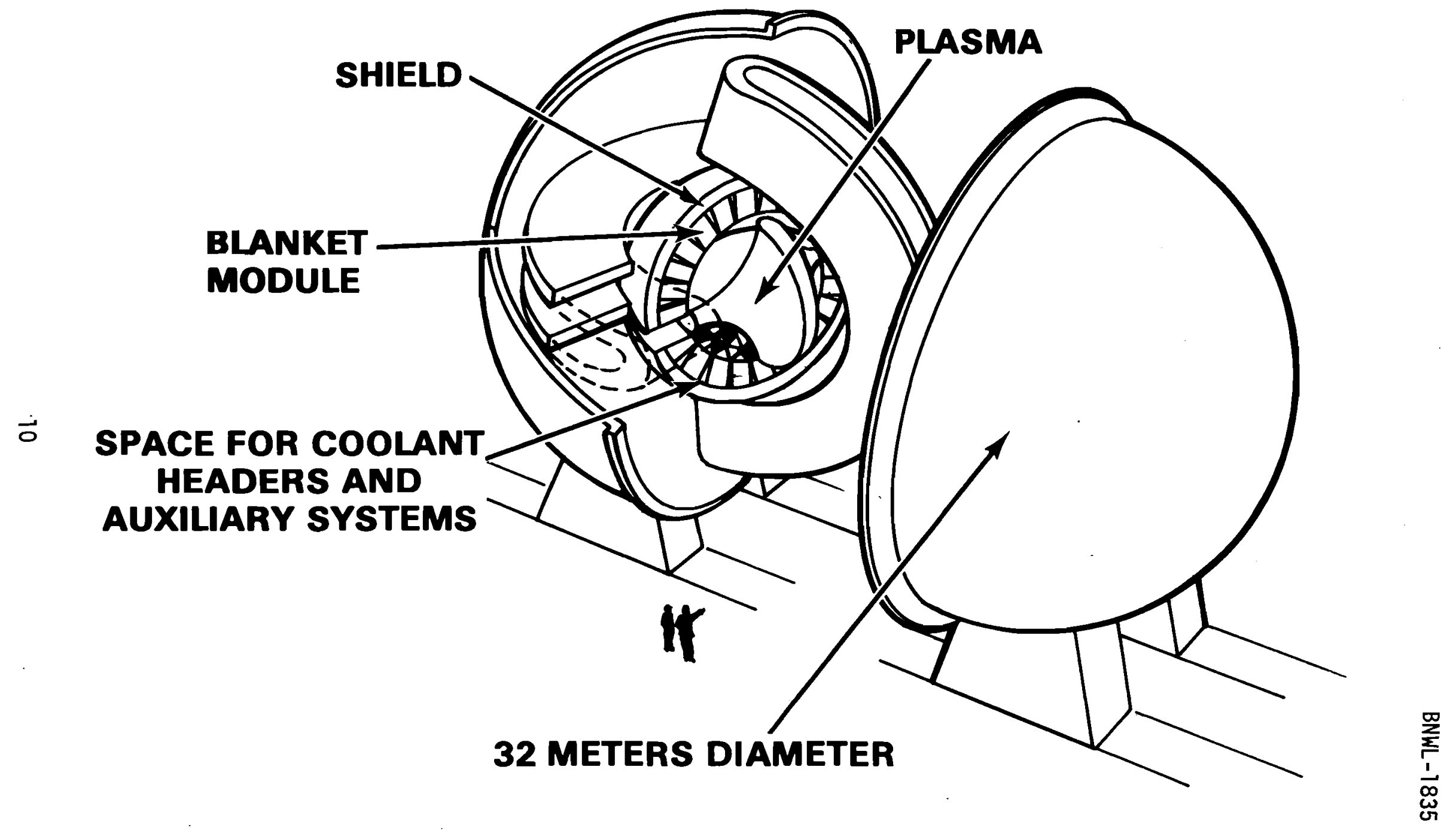

FIGURE 1.1. Mirror Hybrid Reactor 
PRELIMINARY MAGNET DESIGN

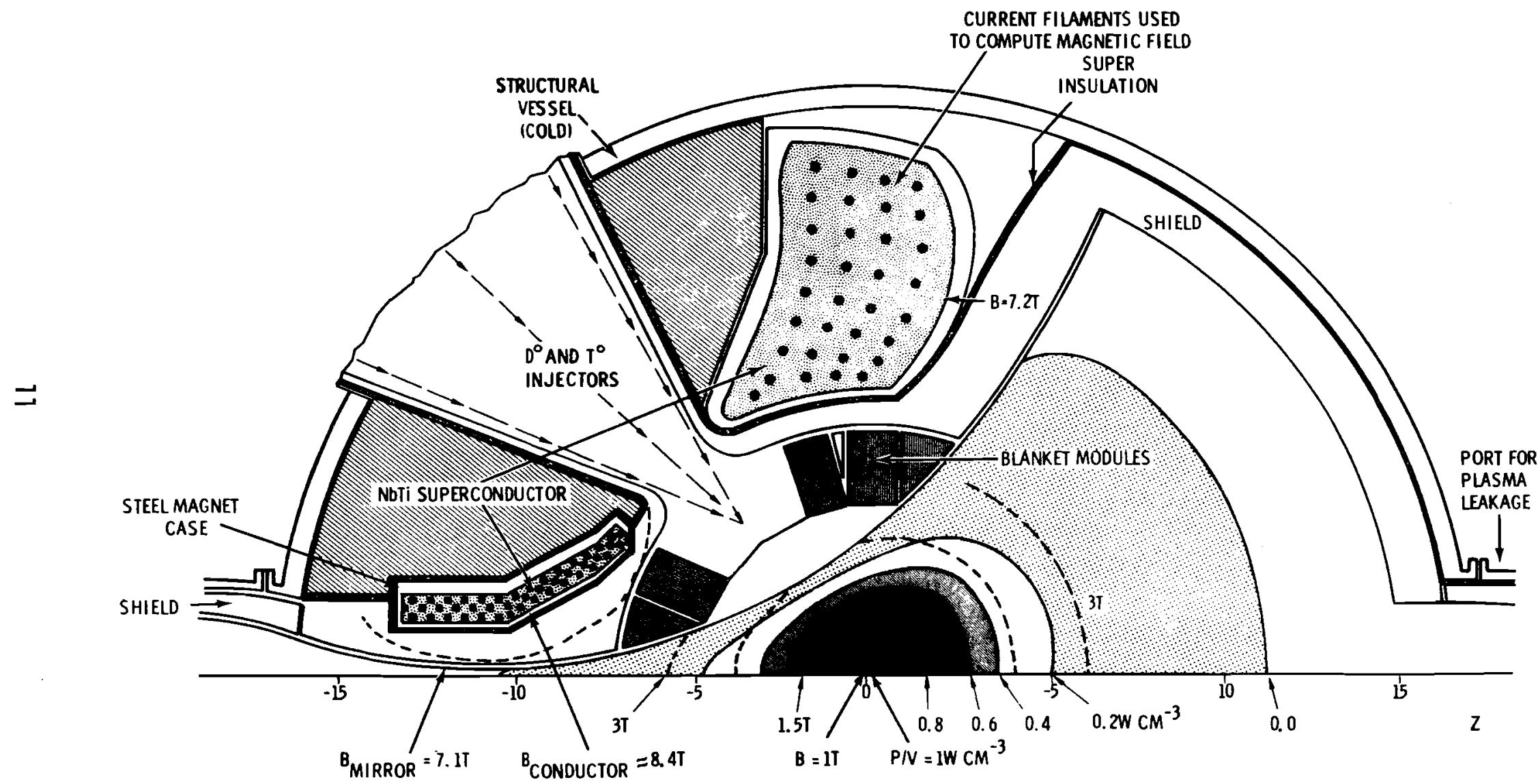

FIGURE 1.2 Preliminary Magnet Design and Magnet Shape 
For a normal mode angular distribution and a mirror ratio of 6.9 , the value of $Q$, where

$$
Q=\frac{\text { fusion power of } 17.58 \mathrm{MeV} / \text { fusion reaction }}{\text { trapped injected power }}
$$

is approximately 0.94 ( 8 , Fig. 3 ) This is the $Q$ value selected for the mirror hybrid reactor and is the value ultimately used in the system parameterization. From Fokker-Planck calculations, the required deuteron current is found to be 2.7 times the triton current. ( 9 ) Thus, the trapped deuteron and triton currents are $366 \mathrm{~A}$ and $136 \mathrm{~A}$ for an injected power of 68.3 MW as derived in Section III.

We have made a preliminary cost estimate for the magnet design developed here, the basis of which is discussed in Reference 6 . For a field of $10 \mathrm{~T}$ at the conductor the total magnet cost is estimated to be $\$ 43$ million. The design, based on the NbTi superconductor, is well within current technology. The development of the $\mathrm{Nb}_{3} \mathrm{Sn}$ superconductor with its higher current density capability should lead to a lower cost. However, a detailed structural design of the magnet system is required in order to more accurately make this determination.

Also, because of increasing interest in the environmental effects of magnetic fields, the far field value is given. The far field in absence of the diamagnetic plasma is dipolar in nature with a dipole moment equal to $1.1 \times 10^{10}$ in mks units. The field falls of as $r^{-3}$ and, at 100 meters in the $Z$ direction, is 22 gauss. At 100 meters in the vertical direction, the field is 11 gauss.

\section{B. INJECTOR DESIGN}

The injection energy was chosen to be $120 \mathrm{keV}$ for $D^{0}$ which is near the peak $Q$ value. At much lower energies the neutral power to the walls becomes appreciable, and at higher energies the conversion efficiency in the gas cell falls rapidly. If direct conversion of unneutralized beams 
is not employed and positive ions are used, then the optimum energy would be lower. Also, the magnet cost is less at lower energies.

The design employs four beam paths in the $Z=0$ plane of Figure 1.2 at angles $\theta=45^{\circ}, 135^{\circ}, 225^{\circ}$ and $315^{\circ}$. The injection is perpendicular to the magnetic field over most of the beam paths. Each beam port is $2.2 \mathrm{~m}^{2}$ in area at the first wall. The current density is approximately $3 \mathrm{~mA} \mathrm{~cm}{ }^{-2}$. This corresponds to two to three blanket modules being removed for each beam line. The line density across the plasma is $1.8 \mathrm{x}$ $10^{16} \mathrm{~cm}^{-2}$ and, at $120 \mathrm{keV}$, the e-folding penetration distance is $4 \mathrm{x}$ $10^{15} \mathrm{~cm}^{-2}$ giving 4.5 e-foldings across the plasma which is thick, but acceptable. The tritium is injected with the same velocity in order to penetrate equally we11. Other beam paths with better penetration which would allow higher values of $\beta$ are possible. (see Figure 13 of Reference 6)

The fraction of the injected beam which is trapped should be about $90 \%$ ( 10 , Fig. 6) The remaining $10 \%$ of the beam ends up on the first wall where a fraction of $i$ ts energy is recovered in the thermal plant. If the neutrals are generated by first accelerating $\mathrm{D}^{+}$and $\mathrm{T}^{+}$ions, then about $45 \%$ can be converted to neutrals. Typical beams, however, also have a fraction of $\mathrm{D}_{2}^{+}$ions which would produce half-energy neutrals that would be short-lived. We assume $80 \%$ of the beam is singly ionized. With an accelerator efficiency of $92 \%$, as in Reference 10 , the efficiency of producing and trapping the beam is denoted by the injection efficiency $\left(\mathrm{N}_{\mathrm{I}}\right)$. In this case,

$$
N_{I}=0.9 \times 0.45 \times 0.8 \times 0.92=0.30
$$

Our assumptions are rather conservative and consistent with our philosophy of using present technology where possible. If we take a less conservative view by assuming there were no half-energy particles and that the unneutralized ions were converted in a $90 \%$ efficient direct converter, as argued to be possible in Reference 10, then $N_{I}$ would be 0.68 . Thus, we see that a "simple" injector is predicted to be $30 \%$-efficient and a "sophisticated" one to be $68 \%$-efficient. 
For the "simple" injector operating at 30\% efficiency, with a $Q$ of 0.94 , the input power required would be $228 \mathrm{MW}$, which represents $26 \%$ of gross electric power for blanket multiplication of 39.8. For the "sophisticated" injector, the input power would be $100 \mathrm{MW}$, representing $11 \%$ of the gross electric power.

In order to conserve the energy of the plasma which leaks out of the system, a one-stage direct converter could be installed. This is predicted $^{(8)}$ to be $45 \%$ efficient at $150 \mathrm{keV}$. To this, a $40 \%$ bottoming cycle could be added, thus capturing more of the lost energy. For a $Q$ of 0.94 and $81 \mathrm{MW}$ of charged power entering the direct convertor, 36 MW would be converted to electricity. An additional 18 MW would be converted in the bottoming cycle.

Very little is presently known about the plasma confinement that can be achieved ( $Q$ ) and about the efficiency and cost of injection systems. Parametric studies at this time might be beneficial in determining relative cost and efficiency of more complicated injectors and direct convertors. 


\section{BLANKET DESIGN}

Having presented the general picture of the mirror hybrid reactor, we will now discuss the design of the fissile blanket used for energy multiplication. We will particularly develop the blanket geometry, material selection, blanket parameterization, blanket component sections, and the neutron and thermal performance of the blanket. In general, we are reporting the work in the chronological order of its development.

The blanket design is based on the convertor/lattice concept previously developed at PNL. (1) The blanket design which we selected is shown in Figure 2.1.

\section{A. BLANKET GEOMETRY}

The energy-producing portion of the plasma for the mirror fusion device used in this reactor is nearly spherical. In order to achieve uniform power production in the blanket region, a spherical or nearly spherical geometric shape was a preliminary design goal. The completely spherical blanket was rejected as a realistic design geometry due to anticipated problems of design and access. The geometric shapes considered here are the icosahedron and several geodesics. (11) The surface of an icosahedron is made up of 20 equilateral triangles and is one of the family of regular polyhedra whose vertices are equidistant from the center. Geodesics are polyhedra and their surfaces are also made up of equilateral triangles; however, the vertices of the triangles on their surface may not be equidistant from the center.

Some of the characteristics of the geometric shapes considered here are given in Table 2.1 for blanket shapes with a maximum inner radius of 5 meters, the nominal inner wall radius as specified by the fusion device. ${ }^{(5)}$ For comparison purposes, the sphere is also listed. In all other cases, the blanket is made up of modules which are equilateral triangular prisms joining only on their inner edge. Thus, triangular gaps appear between the modules which allow space for coolant headers, etc. 


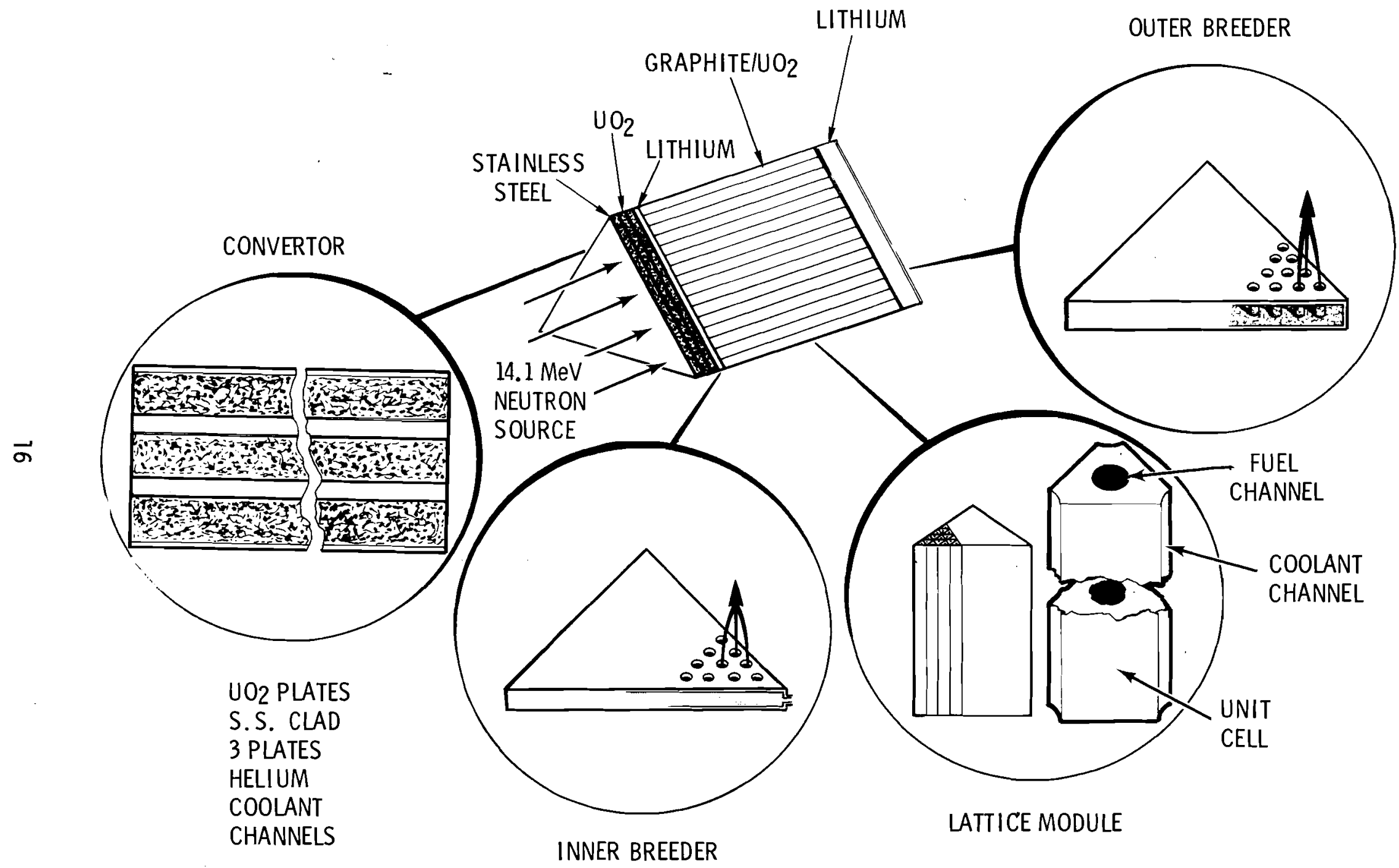

FIGURE 2.1. Hybrid Blanket Module 
BNWL-1835

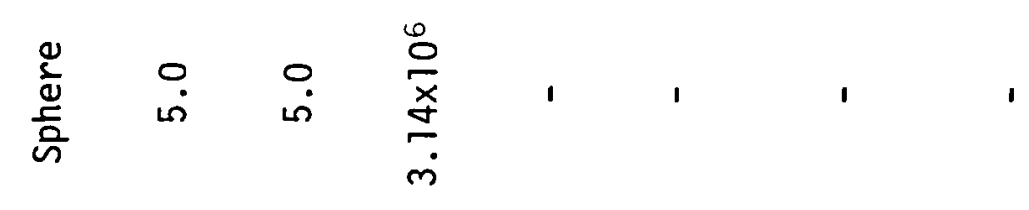

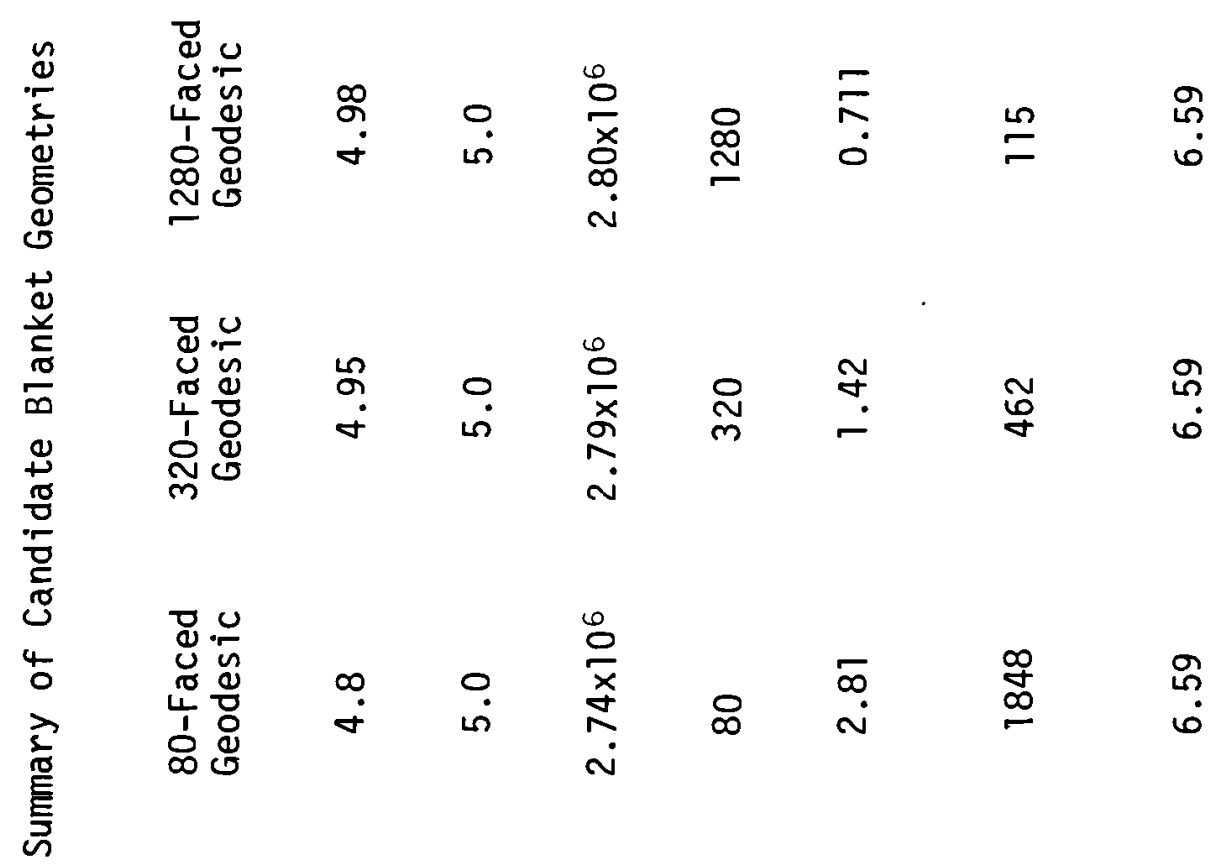

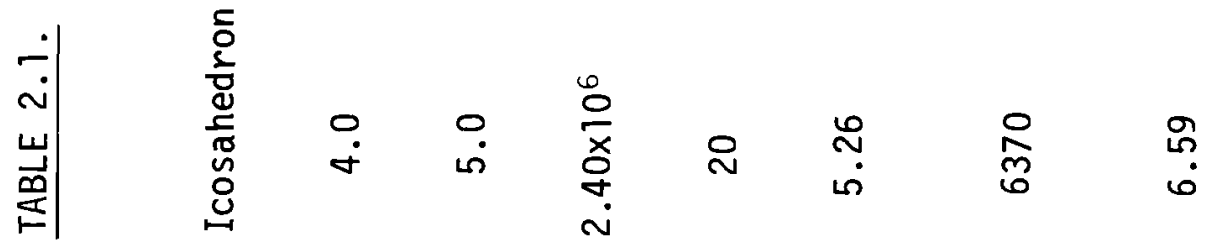

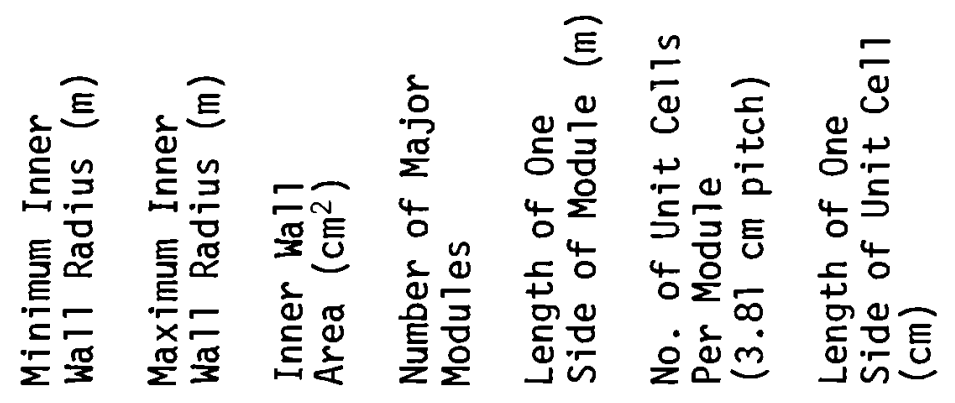


The lattice portion of the module is made up of many smaller equilateral triangular prisms called unit cells. A unit cell consists of one fissile fuel rod, its coolant and its moderator. It is the smallest repeating unit in the lattice design (see Figure 2.1).

Two important criteria govern the selection of a blanket geometry. First, it is desirable to closely approximate the spherical wall area and vacuum wall radius. Secondly, there is a conflicting desire to keep the number of blanket modules to a minimum in order to avoid excess coolant headers. In considering the shapes given in Table 2.1, the 320-faced geodesic and the 1280-faced geodesic are similar in vacuum wall radius and area and both nearly spherical. Neither the 80-faced geodesic nor the icosahedron approximates the sphere nearly as well. The 320-faced geodesic was selected as the blanket design in order to minimize blanket modules and also maintain a close approximation of the spherical shape.

\section{B. LATTICE DESIGN}

Design of the lattice portion of the fissile blanket begins with selection of the basic fission technology. This selection is governed by limiting the choices to those technologies presently employed in operating fission power reactors. In this way, the mirror hybrid design can take advantage of existing technology with consequent minimization of cost and time in future research and development.

The fission technology selected for the lattice region of the blanket is a modification of a High Temperature Gas Cooled Reactor (HTGR) lattice. (12) The selection of the HTGR was based on several factors:

(1) its low parasitic neutron absorption, (2) the apparent compatibility of gas coolant with fusion reactor design, (3) the large heat capacity of the lattice, and (4) the resonance self-shielding properties of the particle fuel employed in HTGR design.

The HTGR lattice consists of fuel rods inserted on a triangular pitch into a graphite moderator. Channels for the gas coolant are dispersed throughout the moderator also on a triangular pitch. The fuel rods consist of ceramic-coated $\mathrm{UO}_{2}$ microspheres formed into cylindrical columns. 
The fuel particles in this design, which are quite small and roughly spherical in shape, consist of uranium oxide particles coated with multiple layers of various graphites and silicon carbide. A description of the fuel particles ultimately selected for this design is given in Table 2.2.

TABLE 2.2. Lattice Particle Fuel Design

\begin{tabular}{clr} 
Region & \multicolumn{1}{c}{ Material } & \multicolumn{1}{c}{ Dimension } \\
1 & $\mathrm{UO}_{2}$ & $1000-\mu \mathrm{m}$ diameter \\
2 & $\begin{array}{l}\text { Porous Pyrolytic } \\
\text { Carbon }\end{array}$ & $50-\mu \mathrm{m}$ thickness \\
3 & $\begin{array}{l}\text { High Density } \\
\text { Isotropic Carbon }\end{array}$ & $20-\mu \mathrm{m}$ thickness \\
4 & Sic (a) & $20-\mu \mathrm{m}$ thickness \\
5 & $\begin{array}{l}\text { High Density } \\
\text { Isotropic Carbon }\end{array}$ & $50-\mu \mathrm{m}$ thickness
\end{tabular}

a. For Fission Product Retention

The initial design decisions required for the lattice region include selection of the fuel particle diameter, the fuel rod diameter and the fuel rod pitch. Later decisions, governed primarily by thermal hydraulics considerations, include the diameter and pitch of the coolant channels. In order to make these selections, a study of the basic HTGR lattice parameters was needed.

The HTGR lattice, at least as employed in the United States, is optimized on the thorium fuel cycle. The nominal HTGR lattice employs $1.27-\mathrm{cm}$ diameter fuel rods arranged on a triangular pitch of $1.85 \mathrm{~cm}$. The fuel particle ranges in size from $0.0381-\mathrm{cm}$ diameter to $0.071-\mathrm{cm}$ diameter depending upon its use (i.e., fissile or fertile). Major considerations in neutronic design of the hybrid are: 
BNWL-1835

- Blanket energy per 14-MeV source neutron (i.e., energy multiplication)

- Tritium breeding $\geq$ unity

- Fission subcriticality

- Temperature effects

- Fertile to fissile conversion ratio near unity.

The factors which determine the above characteristics are fuel particle size, fuel temperature, fuel enrichment and fuel rod pitch. Minimizing the $238 \mathrm{U}$ resonance integral reduces the required $235 \mathrm{U}$ fuel enrichment and optimizes the fissile conversion ratio. We used the GRANIT and EGGNIT computer codes $(13,14)$ to analyze these factors. These codes were developed to calculate properties of particulate fuel. In general, we employed ENDF/B-III nuclear data to perform the analysis.

We first decided on the fuel particle diameter. For a cold 425- $\mu \mathrm{m}$ particle in a $1.27-\mathrm{cm}$ rod on a $1.85-\mathrm{cm}$ pitch with natural enrichment, we found the $238 \mathrm{U}$ resonance integral to be 45 barns. When the particle size was increased to $750-\mu \mathrm{m}$, the resonance integral became 32 barns. To minimize the resonance integral, we selected the largest particle size (1000- $\mu \mathrm{m})$ available with current technology (described in Table 2.2). For $1.27-\mathrm{cm}$ diameter rods with natural uranium at hot operating conditions, we found the resonance integral to be about 35 barns.

One approach to effective lattice design is to assume that the optimum strategy is selection of the highest possible energy multiplication consistent with the desire to breed fissile fuel. The energy multiplication $(M)$ is the fission energy released in the blanket per 14-MeV neutron plus the $14 \mathrm{MeV}$ associated with the fusion neutron divided by the $14 \mathrm{MeV}$ from the fusion neutron. For the fission blanket, $M$ is related to the subcritical neutron multiplication ( $k_{\text {eff }}$ ) of the fission blanket and the average number of neutrons per fission $(v)$ by the equation:

$$
M=\frac{200}{14} \frac{1}{v} \frac{k_{\text {eff }}}{1-k_{\text {eff }}}+1
$$


Equation 2.1 was used only for guidance in the preliminary analysis. For the results reported here, the total thermal energy deposited in the blanket was estimated from the reaction rates calculated in the neutron balance. M was then calculated by dividing by $14.1 \mathrm{MeV}$. The accuracy of this procedure is $~ \pm 5 \%$.

With the particle size selected, a series of calculations for 1000- $\mu \mathrm{m}$ particles with a packaging fraction of $60 \%$ in $1.27-\mathrm{cm}$ diameter rods was performed as a function of the fuel rod pitch, fuel enrichment and fuel temperature. The results of these calculations are summarized in Figure 2.2. The calculations are reported in terms of $\left(k_{\infty}\right)$ neutron multiplication factor, which is the ratio of the number of neutrons resulting from fission in each generation to the number absorbed in the preceeding generation for an infinitely large assembly. ( $\left.k_{\text {eff }}\right)$ is the value of the neutron multiplication factor for an assembly of finite size.) Higher values of $k_{\infty}$ result in higher values of $k_{\text {eff }}$ which ultimately result in higher values of $M$.

Figure 2.2 displays $k_{\infty}$ as a function of fuel pin pitch, fuel enrichment and temperature. The hot operating temperature at which calculations were performed is $1200^{\circ} \mathrm{K}$ for the fuel and moderator. In order to estimate $238 \mathrm{U}$ Doppler and other temperature effects, calculations were also performed at room temperature $\left(293^{\circ} \mathrm{K}\right)$.

Another important parameter besides neutron multiplication is the initial conversion ratio (ICR), the ratio of $238 \mathrm{U}$ captures to $235 \mathrm{U}$ absorptions. It is a measure of the ability of the lattice to produce plutonium. The ICR is plotted as a function of enrichment and fuel rod pitch in Figure 2.3 for $1000-\mu \mathrm{m}$ particle fuel in a $1.27-\mathrm{cm}$ diameter rod.

Figures 2.2 and 2.3 illustrate "tradeoffs" typical in hybrid design. Selection of the fuel pin diameter and particle size determine the effective ${ }^{238} \mathrm{U}$ resonance integral. The neutron resonance escape probability is most sensitive to the fuel pin pitch. Neutron multiplication increases, to a point, with increasing fuel pin pitch and increasing enrichment. Fissile fuel production (ICR) decreases with enrichment and fuel pin pitch. Also, one has to consider the fact that increasing fuel pin pitch results in decreased lattice power density. However, from these 
BNWL -1835

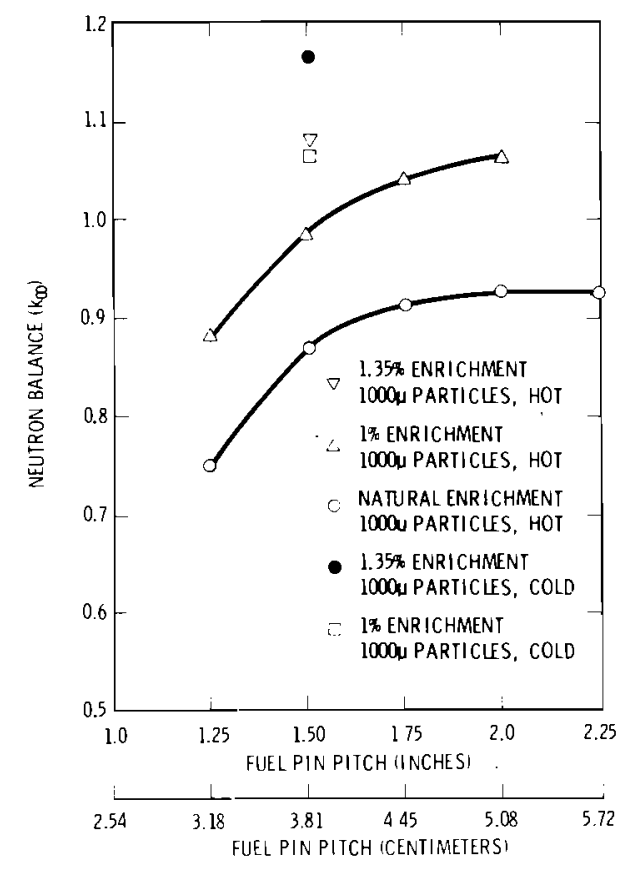

FIGURE 2.2. Neutron Balance versus Fuel Pin Pitch

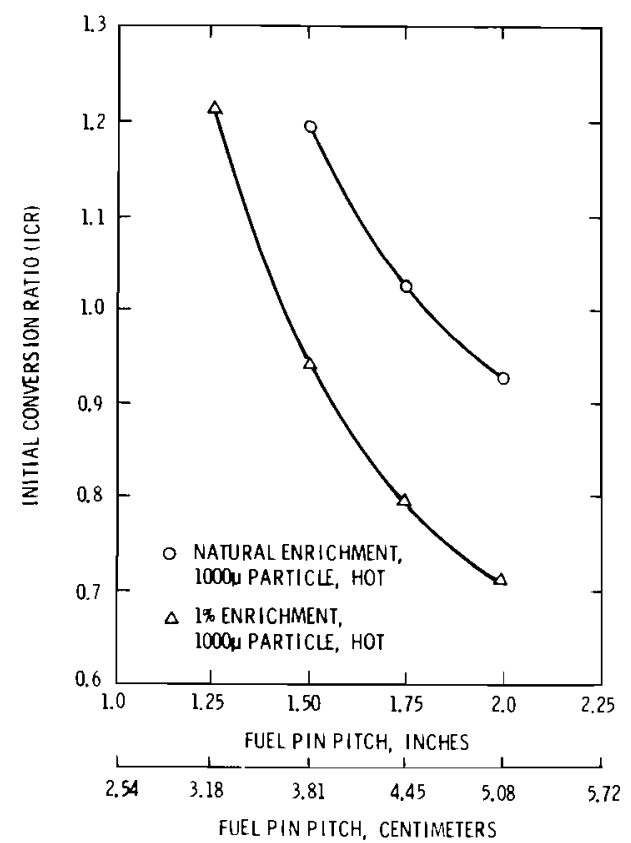

FIGURE 2.3. Initial Conversion Ratio (ICR) versus Fuel Pin Pitch 
figures, it appears that the functional changes in $k_{\infty}$ and ICR with fuel pin pitch have approximately the same behavior, independent of temperature or enrichment. Thus, to some extent, the variables are separable and the fuel pin pitch can provisionally be selected independent of enrichment. A $3.81-\mathrm{cm}$ pitch was selected as a preliminary choice giving adequate energy multiplication and fissile fuel production. After selection of the fuel rod pitch, the unit cell dimensions can then be determined.

The remaining lattice parameter to be selected is the fissile fuel enrichment. Previous analyses $(15)$ have shown that a value of $k_{\text {eff }}$ (the neutron multiplication for the finite blanket) should be of the order of 0.9 for the hot operating blanket to assure both subcritical operation on the one hand, and adequate multiplication on the other. Initial survey calculations based on leakage arguments (employing the buckling expressions shown in Appendix D) indicated that a blanket of these dimensions and materials would have a non-leakage fraction of 0.92 . However, the lithium regions of the total blanket, which will be required for tritium breeding, will be heavy parasitic absorbers of thermal neutrons. Thus, both a minimum $k_{\infty}$ value of approximately 0.98 and a minimum enrichment of $1 \%$ appear essential. Final selection of the lattice enrichment must await design of the total blanket.

The effect of resonance Doppler-broadening and other temperature coefficients can be considered independent of enrichment. For the 1000- $\mu \mathrm{m}$ particle in a $1.27-\mathrm{cm}$ diameter fuel rod at the fuel rod pitch of $3.81-\mathrm{cm}$, the total thermal defect on $k_{\infty}$ in Figure 2.2 is about $7 \%$ for al1 data shown. Therefore, if the hot operating value of $k_{e f f}$ is approximately 0.9 , inadvertent criticality of the lattice due to shutdown or other considerations appears to be impossible.

\section{c. CONVERTOR DESIGN}

The neutron convertor region of the blanket fulfills a quite different role in the hybrid design compared to the lattice region. While the lattice region is developed primarily for energy production, the convertor region takes advantage of the energetic 14-MeV neutrons 
for breeding of fissile fuel from ${ }^{238} \mathrm{U}$ and the multiplication of the 14-MeV neutrons to several lower-energy neutrons by $n, 2 n, n, 3 n$ and $n$, fission reactions on ${ }^{238} \mathrm{U}$. The convertor region produces a relatively small fraction of the total blanket power and, in order to maximize neutron conversion and fissile fuel breeding, requires a relatively high uranium content.

A convertor design of $\mathrm{UO}_{2}$ plates $2-\mathrm{cm}$ thick and clad with $0.1 \mathrm{~cm}$ of stainless steel was selected as the base design. The coolant gaps between plates are $0.8 \mathrm{~cm}$. The coolant is helium which enters at the vacuum wall side of the convertor region and progresses through the coolant gaps between the plates toward the lattice. The plates can be thought of at this stage of design definition as being triangular in shape and the size of a module. Three convertor plates, their coolant gaps, vacuum wall, and structural material constitute the current design. Details are shown in Figure 2.1.

This design is a loose adaptation of plate type fuel technology. The manufacturing process for the plates is assumed similar to that used in production of the Shippingport PWR fuel, which evolved from the Naval Submarine Reactor Program. As will be discussed in the thermal hydraulics section, the thermal requirements on the convertor are such as to allow for this appication. This is fortunate in that the PWR fuel plate technology provides for an expeditious and proven method of obtaining the desired large loading of uranium.

The convertor was not analyzed separately, but was considered in conjunction with the lattice. Thus, its neutronic and thermal characteristics are reported in the section on composite blanket design. Because of data deficiencies, the neutronic methods used for convertor analysis, as discussed in detail in Appendix B, resulted in a under prediction of the neutron production of the convertor! 16$)$ 
BNWL-1835

\section{BREEDER DESIGN}

Two regions for breeding tritium from lithium for fusion device fuel are included in the blanket design. These regions are known as the inner breeder and the outer breeder. The inner breeder is located between the converter and the lattice region. The outer breeder is located between the lattice region and the radiation shield. In concept, both breeder regions have the same design and differ only in their overall thickness.

The breeder regions are triangular prisms of the same triangular dimensions as the blanket modules. At this point in the design, they are conceived of as lithium clad with stainless steel. Coolant channels which line up with the coolant channels in the lattice are included. In later design work, the lithium may be loaded as an alloy with some other metal as has been proposed by various investigators. (17) A primary design consideration was limitation of the breeder-region peak temperature to less than $500^{\circ} \mathrm{C}$ to prevent high lithium corrosion rates.

The breeder regions were analyzed in conjunction with the composite blanket. Thus, their performance is also discussed in the composite design section.

\section{E. COMPOSITE NEUTRONIC BLANKET DESIGN}

The composite blanket is arranged in modules, as shown in Figure 2.1. The blanket design was then subjected to parametric analysis using the ANISN ${ }^{(18)}$ code. The calculations were performed with ENDF/B-III crosssection data in 27 energy groups. The scattering matrices were obtained by collapsing 100-group matrices into 27 energy groups with a neutron spectrum based on an infinite graphite medium. The capture and fission cross sections were developed from EGGNIT and GRANIT calculations. A11 of the neutron balance calculations were made with ANISN in the P-3, S-8 approximation. In the analysis, calculations were performed at operating conditions to balance tritium production, fissile fuel production, and energy multiplication. The major design parameters needed to be selected were the individual region thicknesses and the lattice enrichment. In addition, the need for a reflector outside of the lattice was studied. 
BNWL -1835

The dimensions were selected subject to the constraint of a total blanket module thickness of $200 \mathrm{~cm}$. This is the maximum blanket thickness available from the magnet design while allowing for an additional $100 \mathrm{~cm}$ of radiation shield.

Because of the several parameters which needed to be fixed by the composite blanket analysis, several parametric searches were performed. Representative calculations for the composite blanket are shown in Table 2.3.

For this table, Case 1 represents the initial design concept. It employs a three-plate convertor, a $150-\mathrm{cm}$ lattice region and a $20-\mathrm{cm}$ reflector between the lattice and outer breeder. The lattice has an enrichment of $1 \%$, determined previously as the probable minimum requirement. This design is a prolific fissile breeder, a poor tritium breeder, and can be classed as a low energy multiplication system. Thus, this design is unsatisfactory. Case 2 is an attempt to increase tritium breeding by combining the inner breeder and convertor into a homogeneous region. Tritium production decreases by $5 \%$, fissile breeding decreases by $1 \%$, and energy multiplication increases by $5 \%$. Therefore, there seems to be no marked advantage to mixing the convertor and the inner breeder. Case 3 is a variation of Case 2 whereby the reflector and part of the outer breeder are replaced by fuel and a different convertor/breeder mixture is used. Compared to Case 2, tritium production drops $50 \%$, fissile breeding increases $3 \%$, and energy multiplication $27 \%$. This case seems to lack sufficient lithium in the inner region. In addition, the presence of the reflector does not result in an acceptable design and it takes space which could be used by fuel. Case 4 is again a variation of Case 1 without a reflector with no significant change in any of the parameters.

None of the Cases 1 through 4 represents acceptable designs. The mirror hybrid must breed fissile and fusion fuel while producing several times the power of its fusion device. They are all low in energy production, they are dismal tritium breeders, and they are all excellent fissile breeders. Taken as a whole, however, they do demonstrate that a reflector is unnecessary and that it is unnecessary to mix the convertor/ 
TABLE 2.3. Mirror Hybrid Composite Blanket Analysis

\begin{tabular}{|c|c|c|c|c|}
\hline $\begin{array}{l}\text { Case } \\
\text { No. } \\
\end{array}$ & & $\begin{array}{c}\text { Fusion } \\
\text { Breeding } \\
\text { Ratio }\end{array}$ & $\begin{array}{c}\text { Fission } \\
\text { Breeding } \\
\text { Ratio } \\
\end{array}$ & $\begin{array}{c}\text { Energy } \\
\text { Multiplication }\end{array}$ \\
\hline 1 & $\begin{array}{l}8.5-\mathrm{cm} \text { convertor } \\
1.5-\mathrm{cm} \text { breeder } \\
150-\mathrm{cm} \text { lattice }(1.0 \mathrm{E})(\mathrm{a}) \\
20-\mathrm{cm} \text { reflector } \\
20-\mathrm{cm} \text { breeder }\end{array}$ & 0.77 & 1.59 & 19 \\
\hline 2 & $\begin{array}{l}10-\mathrm{cm} \text { convertor-breeder mix }(\mathrm{b}) \\
150-\mathrm{cm} \text { lattice }(1.0 \mathrm{E}) \mathrm{a} \\
20-\mathrm{cm} \text { reflector } \\
20-\mathrm{cm} \text { breeder }\end{array}$ & 0.73 & 1.57 & 20 \\
\hline 3 & $\begin{array}{l}10-\mathrm{cm} \text { convertor-breeder mix }(\mathrm{c}) \\
180-\mathrm{cm} \text { lattice }(1.0 \mathrm{E})^{\mathrm{a}} \\
10-\mathrm{cm} \text { breeder }\end{array}$ & 0.37 & 1.62 & 25 \\
\hline 4 & $\begin{array}{l}8.5-\mathrm{cm} \text { convertor } \\
1.5-\mathrm{cm} \text { breeder } \\
180-\mathrm{cm} \text { lattice }(1.0 \mathrm{E})(\mathrm{a}) \\
10-\mathrm{cm} \text { breeder }\end{array}$ & 0.74 & 1.55 & 20 \\
\hline 5 & $\begin{array}{l}8.5-\mathrm{cm} \text { convertor } \\
1.5-\mathrm{cm} \text { breeder } \\
180-\mathrm{cm} \text { lattice }(1.25 \mathrm{E})^{(\mathrm{a})} \\
10-\mathrm{cm} \text { breeder }\end{array}$ & 0.89 & 1.22 & 32 \\
\hline 6 & $\begin{array}{l}8.5-\mathrm{cm} \text { convertor } \\
1.5-\mathrm{cm} \text { breeder } \\
180-\mathrm{cm} \text { lattice }(1.50 \mathrm{E})(\mathrm{a}) \\
10-\mathrm{cm} \text { breeder }\end{array}$ & 1.26 & 0.984 & 50 \\
\hline 7 & $\begin{array}{l}8.5-\mathrm{cm} \text { convertor } \\
1.5-\mathrm{cm} \text { breeder } \\
180-\mathrm{cm} \text { lattice }(1.35 \mathrm{E})^{(\mathrm{a})} \\
10-\mathrm{cm} \text { breeder }\end{array}$ & 1.00 & 1.11 & 40 \\
\hline
\end{tabular}

a. $235 \mathrm{~J}$ enrichment in atom percent.

b. Represents 85-15\% convertor/breeder mixture.

c. Represents $98 \%$ - $2 \%$ convertor/breeder mixture. 
BNWL -1835

inner breeder which would lead to a more complex design.

Previous studies (15) have shown that the key to hybrid design is high neutron multiplication. Cases 1 through 4 all have relatively low neutron multiplication indicating that $k_{\text {eff }}$ should be increased. Thus, a search on lattice enrichment seemed in order.

Case 5 is a variation of Case 4 with an enrichment of $1.25 \%$ in the lattice. Energy multiplication is increased by $59 \%$, tritium breeding by $21 \%$ and fissile breeding is decreased by $21 \%$. Thus, this enrichment increase, while not yielding a result which is entirely favorable, does result in changes in the desired directions.

In Case 6 , the enrichment is increased to $1.5 \%$ with other parameters held constant. Relative to Case 5 , this design increases energy multiplication from 32 to 60 . For the first time a tritium breeding ratio greater than unity is observed and a fissile breeding ratio less than unity is observed. This enrichment is too high for the desired results.

Case 7 describes the design finally settled on. A tritium breeding ratio of unity and a fissile breeding ratio of 1.1 were observed, along with an energy multiplication of 40 . The tritium breeding in this design is limited by the thickness of the inner breeder region. Calculations to be reported at a later date show that increasing the inner breeder region at the expense of the outer breeder region increase the total tritium breeding. The implied value of $k_{\text {eff }} \sim 0.88$ for the total blanket more than meets safety criteria. (The value of $k_{\text {eff }}$ is calculated by Equation 2.1 using the value of $M$ from the computer calculation and also by direct analysis of the ANISN output.) The need for the device to breed its own fuel and export plutonium is met by the breeding ratios. The energy multiplication results in relatively modest fusion device requirements. The design given in Case 7 is subjected to a thermal-hydraulics analysis in the following section.

Taken as a whole, Cases 1 through 7 demonstrate the complex relationships between tritium breeding, fissile breeding, and energy multiplication 
BNWL -1835

found in hybrid reactor blankets. One finds that the breeding functions tend to compete for the neutrons. However, at sufficiently high energy multiplication, there seem to be enough neutrons available to fulfill all the desired roles.

F. THERMAL HYDRAULICS ANALYSIS

Mathematical Model

A digital computer code called TRUTH ${ }^{(2)}$ was developed to aid in determining the steady state and transient thermal performance of the blanket. The mathematical model consisted of an energy balance between any arbitrary collection of interconnected subvolumes. The resulting equations were solved with an explicit numerical procedure which computed total heat exchange between subvolumes by the use of previously calculated temperatures and thermal resistances. (19) The temperature of each subvolume was updated on the basis of its total heat capacity and the energy it received from adjacent subvolumes during a time step.

The thermal resistance between nodes optionally includes the effects of conduction, forced and free convection, radiation and fluid flow. The conduction resistance is considered to be constant whereas the respective surface coefficients for the other heat transfer mechanisms are treated via correlations with temperature or flow rate as independent variables.

The nodalization which is illustrated in Figure 2.4 consists of 54 nodes and 90 connections. It was used to model the blanket and shield for transient problems. A much more complex network of 80 nodes and 143 connections was used for steady state analyses to provide additional detail.

Steady State Analysis

Steady state temperature fields were calculated for lattice power densities between 2.2 and $6.8 \mathrm{MW} / \mathrm{m}^{3}$. The helium coolant flow rate was adjusted to maintain an inlet-exit temperature rise of $528^{\circ} \mathrm{C}$ (from $288^{\circ} \mathrm{C}$ to $816^{\circ} \mathrm{C}$ ). The resulting peak temperatures for the major components are shown in Figure 2.5 as a function of lattice power density. Note that the temperatures of the shield and breeders remain nearly constant below 


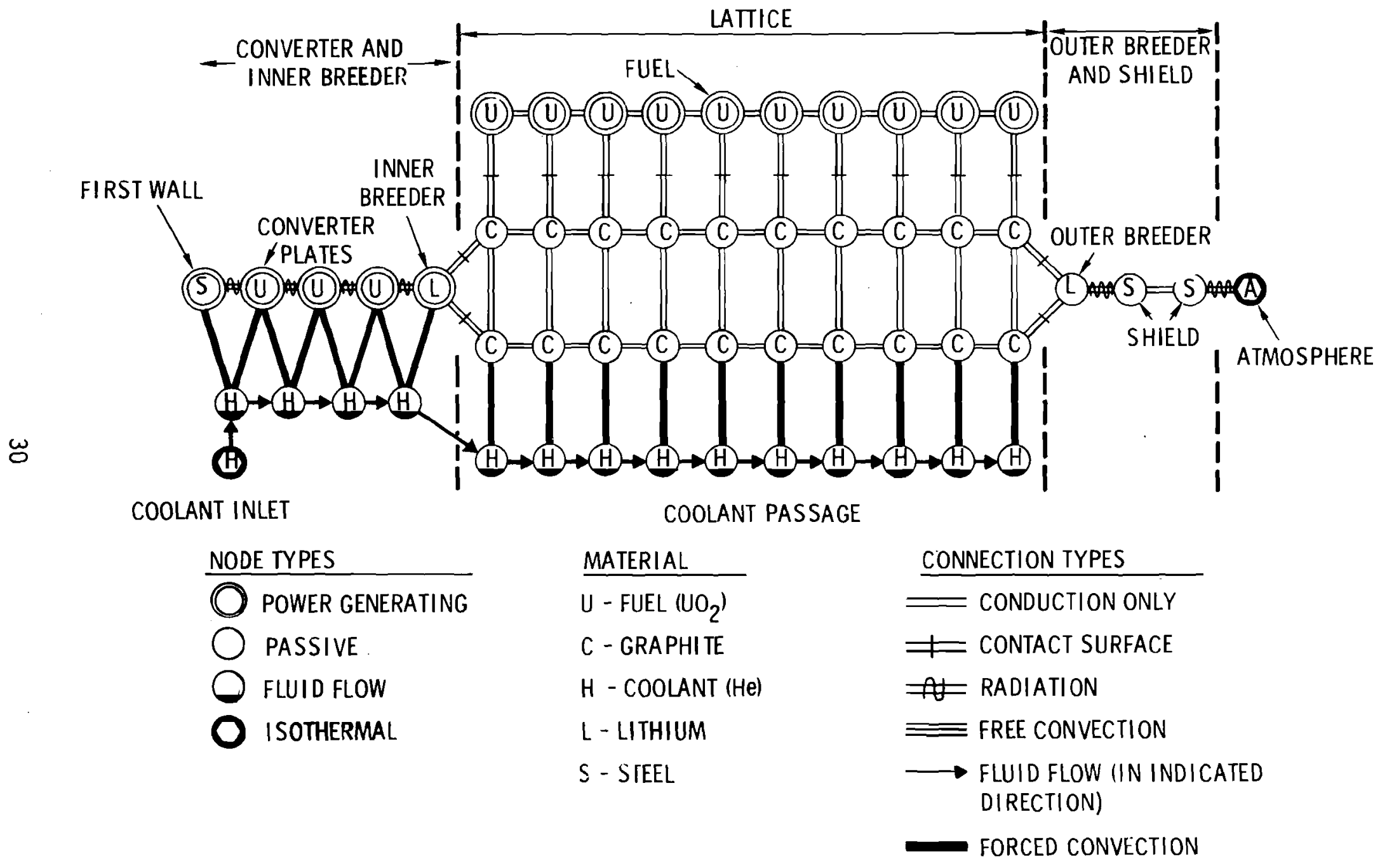




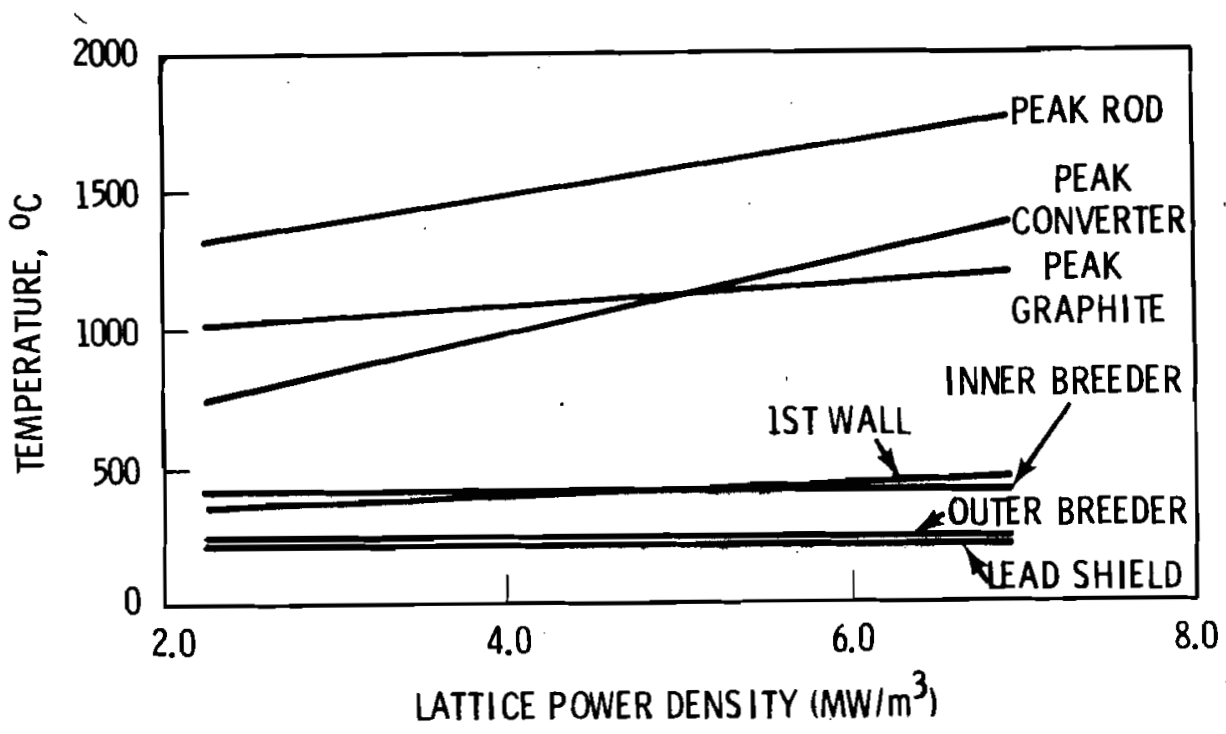

FIGURE 2.5. Effect of Power on Temperatures with Constant-Coolant Temperature Rise

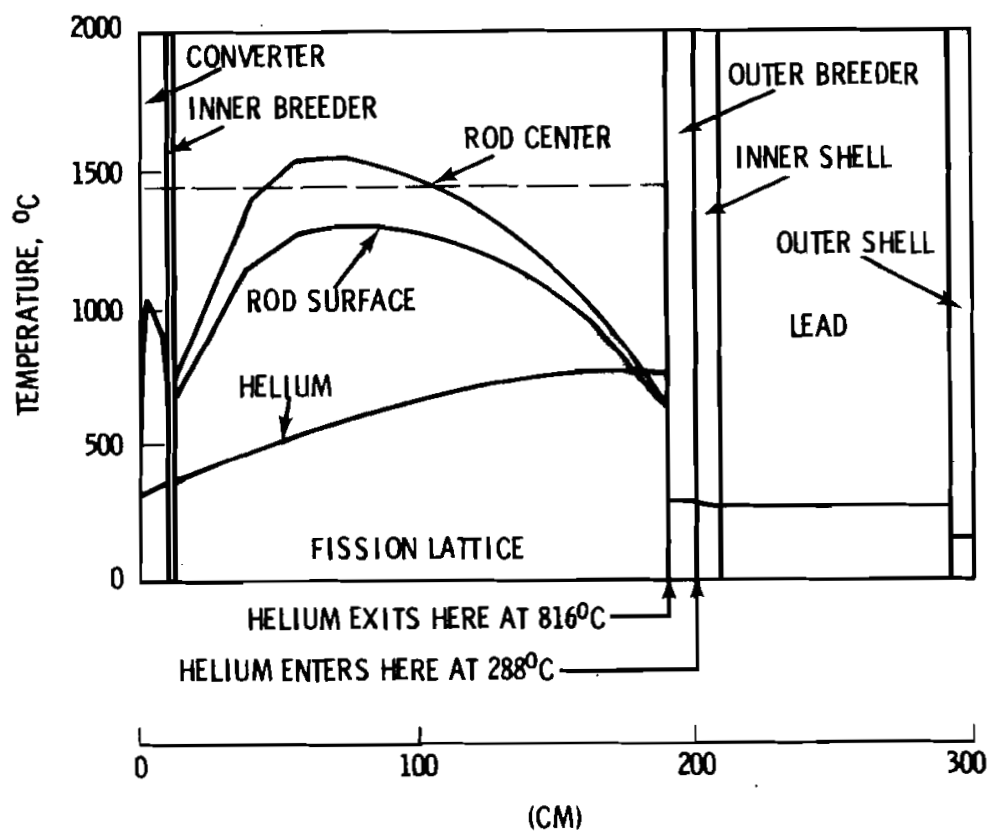

FIGURE 2.6. Steady State Temperature Distribution 
BNWL-1835

$500^{\circ} \mathrm{C}$. These regions are located such that their temperatures depend primarily on the helium inlet temperature and, therefore, are almost independent of the power level of the device. At the design point of $4.3 \mathrm{MW} / \mathrm{m}^{3}$, the peak fuel center temperature is $1566^{\circ} \mathrm{C}$. This is above the maximum design temperature criterion of $1410^{\circ} \mathrm{C}$ at which cracks may form in the coating of the central fuel particles. (20) However, since the rod surface peak temperature is $1316^{\circ} \mathrm{C}$ at this power level, a secondary silicon carbide coating around the entire fuel pin could be added to serve as an effective barrier to fission product diffusion. This, however, is not current technology. Due to the sharp power profile of the initial design, temperatures above $1410^{\circ} \mathrm{C}$ occur only in a very limited region of the lattice as shown in Figure 2.6. It is expected, therefore, that more uniform power distributions will be achieved in the future to limit peak fuel temperatures and thereby ensure fuel particle coating integrity.

An adjustment in the power distribution may not only reduce the peak temperature of the device at $4.3 \mathrm{MW} / \mathrm{m}^{3}$ but could potentially permit an increase in power of up to $50 \%$ for the same peak temperature. For the most efficient thermal performance of the lattice, rod center temperatures should be uniform. It can be shown that this will be achieved with the following exponential power profile.

$$
\begin{aligned}
P / \bar{P} & =\frac{a e^{-a}}{\left(1-3^{-a}\right)} \\
a & =\frac{U A}{m c}\left(\frac{X}{L}\right)
\end{aligned}
$$

where $P / \bar{P}$ is the ratio of local power density to the averag, UA is the product of fuel-center-to-coolant heat conductance and coolant channel surface area, $\mathrm{mc}$ is the product of coolant mass flow rate and its specific heat, and $(X / L$ is the relative distance from the lattice inlet. The above ideal profile and the current design distribution are compared in Figure 2.7 and the effect of each on the overall temperature field is illustrated in Figure 2.8, as determined by the TRUTH code. Except for end effects, the rod center temperatures are uniform 


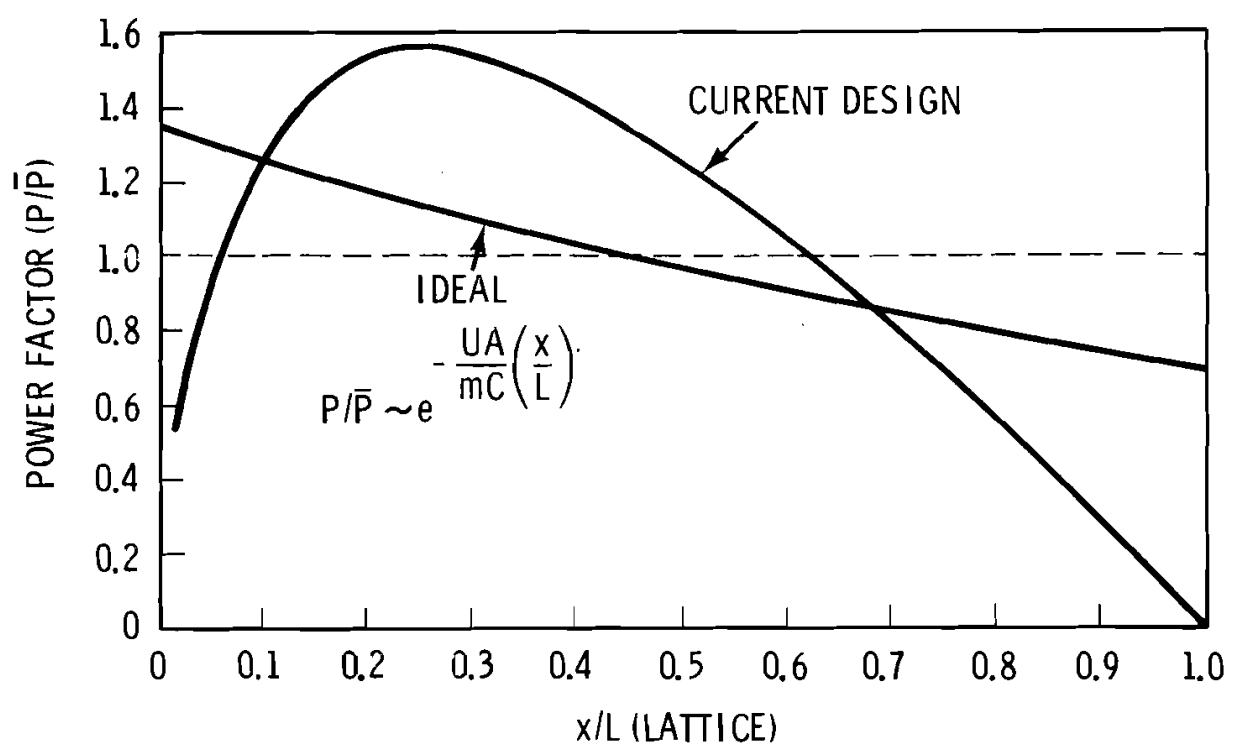

FIGURE 2.7. Comparison of Power Profiles

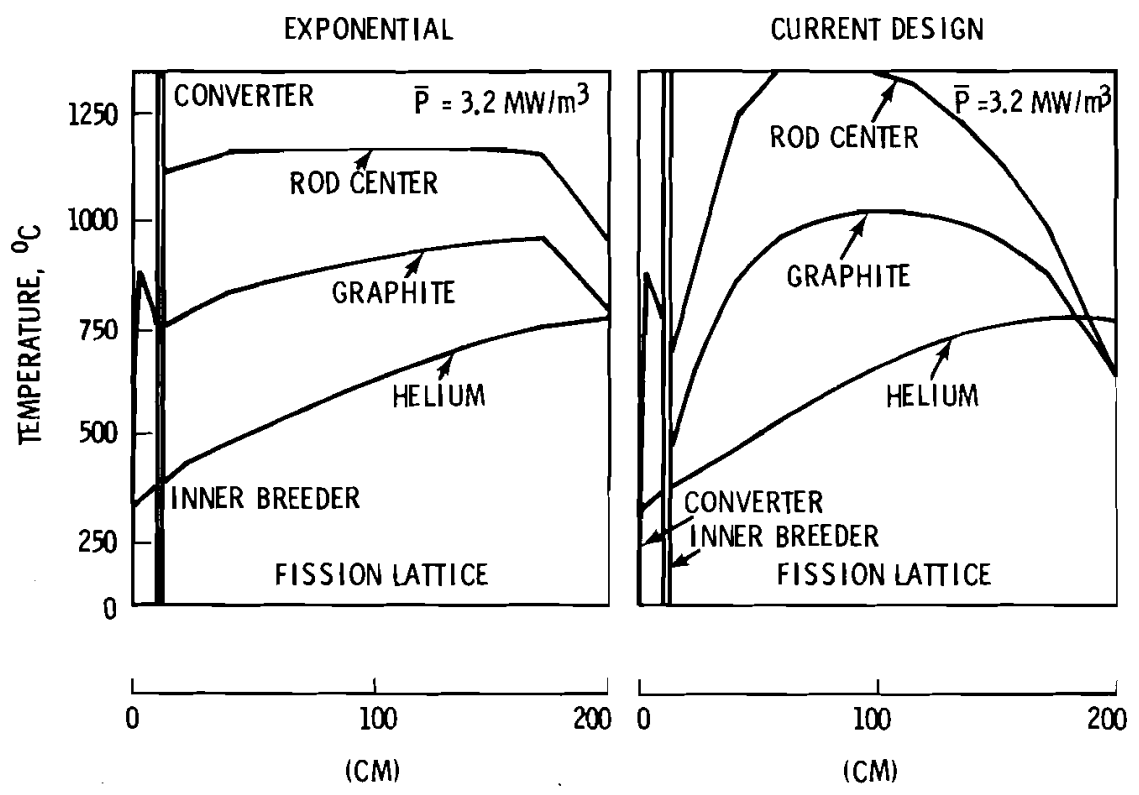

FIGURE 2.8. Effect of Power Distribution on Lattice Temperatures 
BNWL-1835

with the exponential power profile. Note that the helium and convertor temperatures are relatively unaffected. The particular analysis reported in Figure 2.8 uses a power density of $3.2 \mathrm{MW} / \mathrm{m}^{3}$. The same relative effects would be observed at the design value of $4.3 \mathrm{MW} / \mathrm{m}^{3}$.

Transient Analysis

Since a loss of coolant (LOCA) accident is one of the few credible incidents associated with the hybrid, a transient LOCA analysis was performed using the TRUTH code.

A completely definitive transient LOCA analysis required definition of all major heat sinks and conduction paths between the core and the atmosphere. The current mirror hybrid design does not yet provide this information. However, analysis using a simplified model will reveal the magnitude of the emergency cooling capacity required to dissipate core decay heat while limiting peak temperatures in the device. For the transient, the shield was assumed to be a solid stainless steel spherical she11 radiating directly to the atmosphere. The actual design calls for a lead and steel shield. Modeling of the heat transfer phenomena of lead under these conditions will be accomplished at a later date. No other heat sirks were considered. In this analysis, all coolant was instantaneously lost at the same time that the reactor was shut down. Radioactive decay heat from the fission products provided the primary heat source.

As shown in Figure 2.9, a peak temperature of approximately $2010^{\circ} \mathrm{C}$ is predicted at about 55 hours after shutdown. The melting point of $\mathrm{UO}_{2}$ is $2450^{\circ} \mathrm{C}$. The $400^{\circ} \mathrm{C}$ margin between the predicted fuel temperature and the fuel melting temperature, with no emergency cooling would appear sufficient to tentatively state that blanket meltdown would not occur following a loss of coolant accident in the Mirror Hybrid for the conditions analyzed. 
BNWL-1835

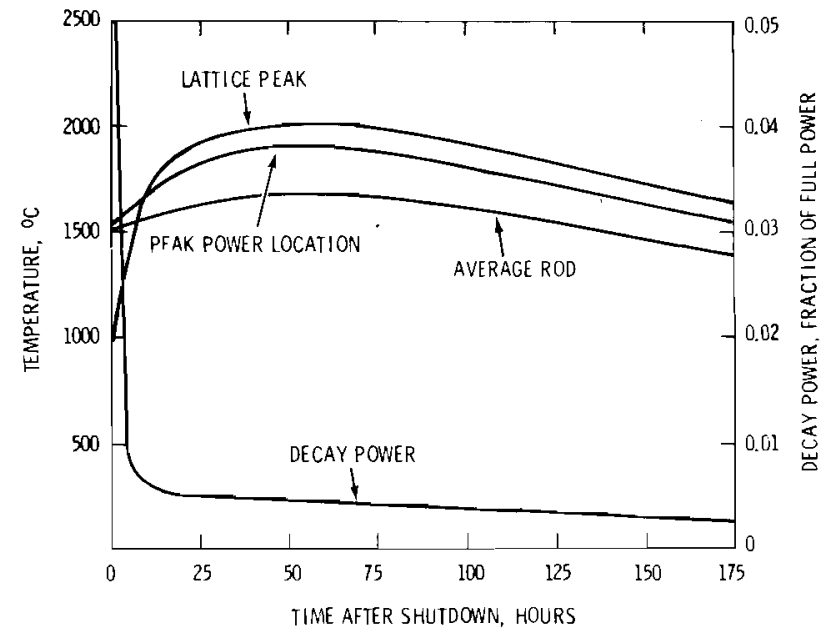

FIGURE 2.9. LOCA Transient Temperatures

The ability of the mirror hybrid design to absorb large amounts of decay heat following a LOCA without rapid temperature excursions was demonstrated by making a run with the blanket perfectly insulated. In this case no fuel melting was predicted until over 4 days after shutdown. Therefore, it seems that shield or convertor auxiliary cooling should very easily be able to keep peak temperatures even below normal operating conditions for the most severe LOCA.

This enormous heat capacity is a positive feature of the mirror hybrid blanket design which is similar to the High Temperature Gas Cooled Fission Reactors. (12) To increase the resonance escape probability and stay within existing technology, the fuel pin pitch was expanded. This results in a relatively larger amount of graphite and a somewhat lower power density than is common in the gas-cooled reactors. This pitch expansion ultimately provides the safety margin for LOCA. 


\section{SYSTEM DESIGN}

In previous sections, the problems of neutronics, blanket design, and fusion reactor design have been considered in some detail. All of these areas are important component parts for a hybrid reactor design. These components must now be fitted together to develop a reactor design which is internally consistent and which has parameters in the range of interest for electrical power production.

\section{A. ANALYTICAL MODEL}

The important parameters of the hybrid reactor include net electrical power $\left(P_{N E T}\right)$, system efficiency $\left(N_{S}\right)$, fission blanket energy multiplication $(M)$, injector efficiency $\left(N_{\mathrm{I}}\right)$, thermal to electrical conversion efficiency $\left(N_{T}\right)$, and plasma energy multiplication $(Q)$. These parameters have been combined into the three relationships'given below according to an approach suggested by Werner $(21)$. The equations ${ }^{(a)}$ are:

$$
\begin{aligned}
& N_{S}=N_{T}\left[1-\frac{\left(1-N_{T}\right)}{Q(0.8 M+0.2) N_{T} N_{I}}\right] \\
& P_{N E T}=P_{B} N_{T}\left[1+\frac{.25}{M}-\frac{\left(1-N_{T}\right)}{0.8 M N_{I} N_{T} T^{Q}}\right] \\
& P_{B}=0.8 Q M P_{i n j}=0.8 M P_{F U S}
\end{aligned}
$$

where:

$$
\begin{aligned}
& N_{S}=\text { overall system efficiency } \\
& N_{T}=\text { thermal to electrical conversion efficiency } \\
& Q \quad=\text { plasma energy multiplication } \\
& M \quad=\text { fissile blanket energy multiplication } \\
& N_{I}=\text { injector efficiency } \\
& P_{\text {NET }}=\text { net electrical output }
\end{aligned}
$$

a. The efficiency values used in the equations are fractional, i.e., 0.40 instead of $40 \%$. 


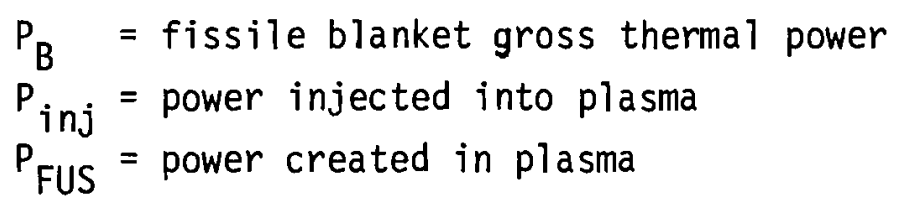

A complete development of these relationships can be found in Appendix C. The equations given will be used here first to parameterize the hybrid reactor and then to select a set of design parameters.

\section{B. SYSTEM PARAMETERIZATION}

In order to develop the regime of permissible plant parameters, some of the variables in the equation must be held constant. A thermal efficiency $\left(\mathrm{N}_{T}\right)$ of $39 \%$ was selected based on HTGR technology $(12)$ and the thermal hydraulics analysis reported in Section II. In addition, the therma 1 hydraulics analysis determined that a lattice power density of $4.3 \mathrm{~W} / \mathrm{cm}^{3}$ and a convertor power density of $18.4 \mathrm{~W} / \mathrm{cm}^{3}$ were acceptable average values for these regions. With the volumes of the lattice and convertor regions, these values can be used to calculate the thermal power output $\left(P_{B}\right)$ of the blanket. The total possible vacuum wall area for the blanket is $2.79 \times 10^{6} \mathrm{~cm}^{2}$. The total possible convertor volume is $2.37 \times 10^{7} \mathrm{~cm}^{3}$ and the total possible lattice volume is $5.02 \times 10^{8} \mathrm{~cm}^{3}$. Thus, the total possible thermal power from the blanket is 2596 MWt. However, space must be left in the blanket to allow for injection and leakage ports. In this design, this amounts to approximately $21 \%$ of the tota 1 possible blanket volume (about 68 modules). Therefore, the blanket thermal power $\left(P_{B}\right)$ is calculated to be $2045.5 \mathrm{MWt}$. Finally, the neutronics analysis determined that the blanket multiplication (M) for the blanket design selected is 40 . With these values, the equations can be reduced to:

$$
\begin{aligned}
& N_{S}=0.39-\frac{.019}{Q N} \\
& P_{\text {NET }}=802.7-\frac{39.186}{Q N_{I}}
\end{aligned}
$$




$$
P_{i n j}=\frac{64.2}{Q}=\frac{P_{F U S}}{Q}
$$

These equations can then be plotted as a function of the designated independent variables.

Figure 3.1 is a plot of the results of Equations 3.4 and 3.5 . In this figure, the net electrical output $\left(P_{N E T}\right)$ and the system efficiency $\left(N_{S}\right)$ are plotted as a function of the product $\left(N_{I} Q\right)$. From the equations, one can see for the present design that for sufficiently large values of the product $\left(N_{I} Q\right)$, the net electrical output approaches 2800 MWe and the system efficiency approaches 39\%. From the figure, it appears that values of $N_{I} Q>0.4$ result in diminishing returns both with regard to net electrical output and system efficiency.

Figure 3.2 is a plot of Equation 3.4. In this plot, however, the product of the variables $\mathrm{N}_{\mathrm{I}} \mathrm{Q}$ is separated. That is, in this figure, the system efficiency $\left(N_{S}\right)$ is plotted as a function of $Q$ for various values of injector efficiency $\left(N_{I}\right)$. The injector efficiencies used on this plot are characteristic of various levels of technology. However, at sufficientiy high values of $Q$, the injector efficiency is not an important parameter in determining system efficiency. That is, for sufficiently high $Q$ values and fixed injector efficiencies, the system efficiency and indeed, the net electrical output approach the asymptotic values noted above. Independent of injector efficiency, increases on system efficiency appear to diminish for values of $Q>1$. Thus, parameterization of the proposed design reveals asymptotic 1 imits on $P_{N E T}$ and $N_{S}$, and, in addition, reveals points of diminishing return on the product $\mathrm{N}_{\mathrm{I}} \mathrm{Q}$ and the parameter $\mathrm{Q}$.

\section{SYSTEM PARAMETER SELECTION}

The blanket thermal power has been determined to be $2045 \mathrm{MWt}$. With this value and an energy multiplication of 40 , determined by the neutronics analysis, one can use Equation 3.3 to determine a value of the fusion thermal power $\left(P_{\text {FUS }}\right)$. Thus, $P_{\text {FUS }}$ turns out to be $64.2 \mathrm{MWt}$. As a result of the fusion reactor and magnet design, a value of $Q=0.94$ 


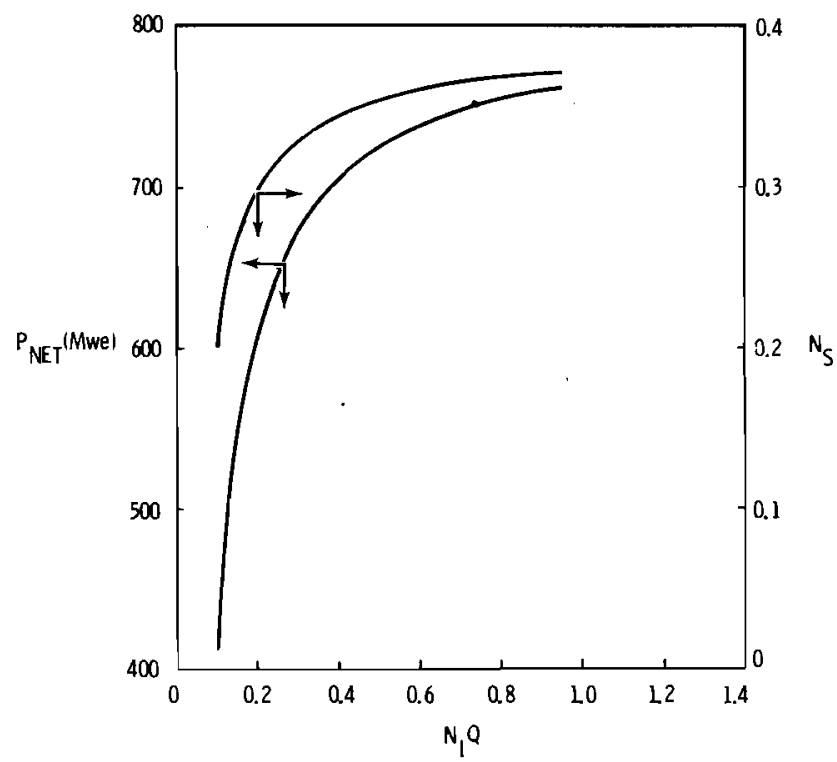

FIGURE 3.1 Net Electrical Output $\left(\mathrm{P}_{\text {NET }}\right)$ and System Efficiency $\left(N_{S}\right)$ as a Function of $N_{I} Q$

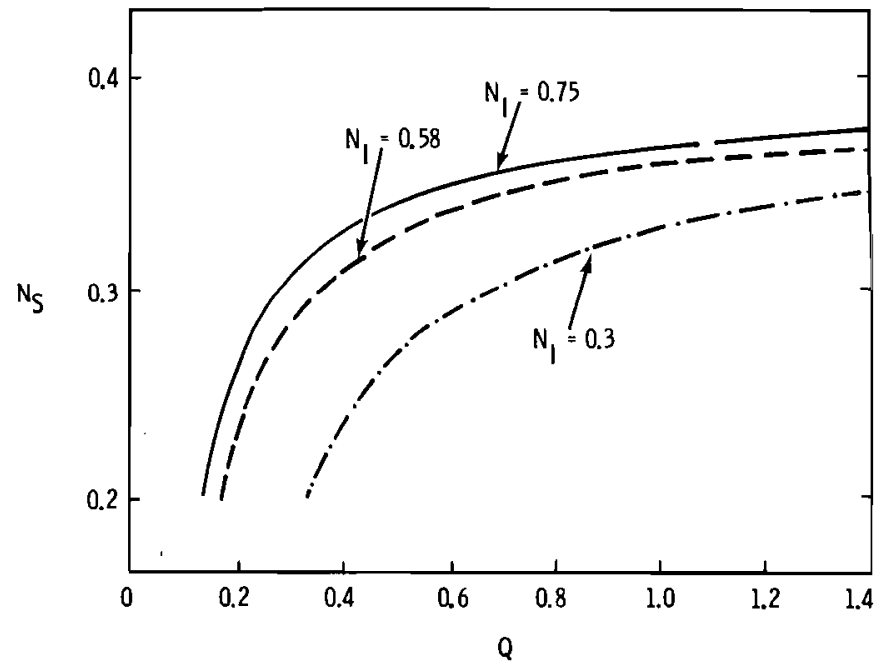

FIGURE 3.2 System Efficiency $\left(\mathrm{N}_{S}\right)$ as a Function of Injector Efficiency $\left(\mathrm{N}_{\mathrm{I}}\right)$ and $Q$ 
was selected. In addition, a value of injector efficiency $\left(N_{I}\right)$ equal to $30 \%$ was selected. This results in a value of 0.282 for the product $\mathrm{N}_{\mathrm{I}} \mathrm{Q}$. From Equation III.6, a value of $Q=0.94$ results in a value of $P_{\text {inj }}=68.3$ MWt. With these values selected, the remaining dependent parameters for the design can be determined from the analytical model.

For the product $N_{I} Q=0.28$, Equation 3.4 yields a value of $N_{S}=0.32$. Additionally, Equation 3.5 yields a value of $P_{N E T}=663$ MWe. The values dictated by the current design are summarized in Table 3.1.

In summary, this analytical model can be used to determine several interesting features of mirror hybrid reactors. First of a11, the desired fusion power ( $P_{F U S}$ ) is linked directly to the blanket design parameters $P_{B}$ and $M$. In addition, any future technology advances which result in higher injector efficiencies can result in operation at lower $Q$ values while maintaining the current net electrical output and system efficiency. Final7y, for the values of $M_{1} N_{I}, N_{T}$, and $P_{B}$ selected here, a breakeven power plant (i.e., one with a zero net electrical output) based on this design would require a $Q=0.16$.

TABLE 3.1 Current Hybrid Reactor Design Parameters

\begin{tabular}{|c|c|c|}
\hline PARAMETER & SYMBOL & $\underline{\text { VALUE }}^{(a)}$ \\
\hline System Efficiency & $\mathrm{N}_{\mathrm{S}}$ & 0.32 \\
\hline $\begin{array}{l}\text { Thermal to Electric } \\
\text { Conversion Efficiency }\end{array}$ & $\mathrm{N}_{T}$ & 0.39 \\
\hline Plasma Energy Multiplication & Q & 0.94 \\
\hline $\begin{array}{l}\text { Fissile Blanket Energy } \\
\text { Multiplication }\end{array}$ & M & 40 \\
\hline Injector Efficiency & $\mathrm{N}_{\mathrm{I}}$ & 0.3 \\
\hline Net Electrical Output & $P_{\text {NET }}$ & $663 \mathrm{MNe}$ \\
\hline Fissile Blanket Thermal Power & $\mathbf{P}_{\mathrm{B}}$ & $2045 \mathrm{MWt}$ \\
\hline Power Injected into Plaṣma & $P_{i n j}$ & $68.3 \mathrm{MW}$ \\
\hline Power Created in Plasma & $P_{\text {FUS }}$ & $64.2 \mathrm{MWt}$ \\
\hline
\end{tabular}

a. The efficiency values used in the table are fractional. 
BNWL-1835

\section{RADIOACTIVE MATERIAL INVENTORY}

As part of the initial design analysis, major components of the radioactive inventory of the mirror hybrid reactor were calculated. (3) The radioactive inventory is useful both as a source for analyzing blanket afterheat effects and for the assessment of operating and safety characteristics of mirror hybrid reactors.

The inventory of radioactive material which accumulates during operation of the hybrid reactor includes fission products, tritium, actinides and activated structure. The latter inventory was not calculated here due to lack of sufficient design definition. It is, however, judged to be small compared to the other components of the inventory.

\section{A. CALCULATIONAL APPROACH}

The fission product and actinide inventories were calculated with the ORIGEN ${ }^{(22)}$ code. The code calculates the fission product and actinide wastes per metric ton of fuel in the reactor. The calculation is performed as a function of fuel exposure and fuel cooling time. The results are available in a number of units including $\mathrm{g} / \mathrm{ton}, \mathrm{g}$-atoms/ton and $\mathrm{Ci} /$ ton.

The tritium inventory for the device is calculated on a much less sophisticated basis. It was assumed that tritium would accumulate in the lithium breeder regions of the blanket to a level at which it could be separated from the lithium. This level was conservatively selected to be $100 \mathrm{ppm}$. With the gram inventory calculated from the level of tritium saturation in lithium and the total lithium inventory, one can then calculate the inventory in curies or other units of radioactivity.

In this analysis, the unit used to report all radioactivity calculations is the toxicity index. The toxicity indices are the base 10 logarithms for the quantity in cubic meters of air, for the inhalation hazard index (or of water, for the ingestion hazard index), required to dilute radioactive material to the limits stipulated in 10 CFR 20, 
Appendix $B .{ }^{(23)}$ These simplified indices provide an overview of the toxicity of wastes based solely on dilution with no allowance for reconcentration or retardation in the environment. The toxicity index provides only an approximate comparison of radiological risk, since it does not allow for accumulation or reconcentration of a nuclide in environmental media, nor for the total impact of a number of nuclides. For limited comparisons, it is an acceptable alternative to dose calculations if used with caution.

The fission product and actinide waste inventories were calculated based upon one year's operation at the appropriate power levels. The saturation inventory for tritium is achieved at times which are short compared to one year. In actual operation, the mirror hybrid reactor might operate with a fuel cycle several years in length. The actual mirror hybrid fuel cycle has not as yet been determined. Thus, the selection of one year's operation for calculation of fuel cycle inventory can be considered arbitrary at this point.

\section{B. INVENTORY ANALYSIS RESULTS}

For the lattice region of the mirror hybrid reactor, the operating power density is $4.3 \mathrm{~W} / \mathrm{cm}^{3}$. A cubic centimeter of the lattice contains, on the average, $0.148 \mathrm{~g}$ of $\mathrm{UO}_{2}$ based upon $528 \mathrm{~g}$ of $\mathrm{UO}_{2}$ per fuel rod. Therefore, on the average, the lattice fuel operates at a power density of $29 \mathrm{MW} /$ metric ton of $\mathrm{UO}_{2}$ or $33 \mathrm{MW} /$ metric ton of $U$. The ORIGEN analys is for the lattice was carried out based on this power density.

The lattice region operating at a power level of $4.3 \mathrm{~W} / \mathrm{cm}^{3}$ for one year, produces $1.32 \times 10^{8} \mathrm{Ci}$ of fission products and $3.67 \times 10^{7} \mathrm{Ci}$ of actinides per ton of fuel. For the inhalation toxicity index, this results in $3.02 \times 10^{16} \mathrm{~m}^{3}$ of air per ton of fuel for fission products and $2.87 \times 10^{16} \mathrm{~m}^{3}$ of air per ton of fuel for the actinides. The lattice region will contain 74.5 metric tons of $\mathrm{UO}_{2}$, assuming 320 complete modules. Therefore, at one year's operation, it will produce $9.83 \times 10^{9}$ $\mathrm{C} i$ of fission products and $2.73 \times 10^{9} \mathrm{C} i$ of actinides. For the inhalation 
toxicity index, this results in $2.25 \times 10^{18} \mathrm{~m}^{3}$ of air for fission products and $2.14 \times 10^{18} \mathrm{~m}^{3}$ of air for actinides.

The convertor region of the mirror hybrid reactor operates at a power density of $18.4 \mathrm{~W} / \mathrm{cm}^{3}$. On the average, a cubic centimeter of the convertor region contains $6.66 \mathrm{~g}$ of $\mathrm{UO}_{2}$ resulting in an average power density of $2.76 \mathrm{MW} /$ ton of $\mathrm{UO}_{2}$. The ORIGEN analysis for the lattice was carried out based on this power density of $2.76 \mathrm{MW} /$ ton of $\mathrm{UO}_{2}$.

The convertor region of the mirror hybrid reactor blanket operating at a power density of $18.4 \mathrm{~W} / \mathrm{cm}^{3}$ for one year, produces $1.27 \times 10^{7} \mathrm{Ci}$ of fission products and $4.71 \times 10^{6} \mathrm{Ci}$ of actinides per ton of fuel. For the inhalation toxicity index, this results in $2.86 \times 10^{15} \mathrm{~m}^{3}$ of air per ton of fuel for fission products and $6.67 \times 10^{16} \mathrm{~m}^{3}$ of air per ton of fuel for the actinides. The convertor region will contain 157 metric tons of $\mathrm{UO}_{2}$ assuming 320 complete modules. Therefore, after one year's operation, the convertor will produce $1.99 \times 10^{9} \mathrm{Ci}$ of fission products and $7.39 \times$ $10^{8} \mathrm{Ci}$ of actinides. For the inhalation toxicity index, this results in $4.49 \times 10^{17} \mathrm{~m}^{3}$ of air for fission products and $1.05 \times 10^{19} \mathrm{~m}^{3}$ of air for the actinides.

The mirror hybrid reactor blanket contains $41.5 \mathrm{~kg}$ of 1 ithium per module. For 320 ful1 modules, the blanket contains 13.3 metric tons of lithium. Assuming saturation and separation at $100 \mathrm{ppm}$, this results in a total tritium inventory of $0.57 \mathrm{~kg}$ of tritium. This is equivalent to $6.65 \times 10^{6} \mathrm{Ci}$. For the inhalation toxicity index, this is equivalent to $3.33 \times 10^{13} \mathrm{~m}^{3}$ of air.

The results of the radioactive inventory analysis for the mirror hybrid reactor are summarized in Table 4.1. This table shows that tritium is a minor fraction of the total radioactive inventory of the blanket. It further demonstrates that the major radioactive inventory is associated with the actinides produced in the convertor region. Notice that, in terms of curies, there are more curies of actinides in the lattice 
than in the convertor, but, in terms of toxicity index, the actinides in the convertor predominate. This apparent contradiction can be explained by the difference in composition of the actinides. The convertor actinides are made up predominantly of ${ }^{239} \mathrm{Pu}$ which has a 24,000 year half life while the lattice actinides include mixtures of ${ }^{239} \mathrm{Pu}, 240 \mathrm{Pu},{ }^{241} \mathrm{Pu}$, and several of the higher actinides. The net result is a shorter mixture of half life for the lattice actinides which result in a higher curie content. However, when the toxicity index is calculated, the relative hazard of ${ }^{239} \mathrm{Pu}$ is such that the convertor actinides predominate.

TABLE 4.1. Radicactive Inventory of Mirror Hybrid Reactor

\begin{tabular}{|c|c|c|c|}
\hline & Curies & $\begin{array}{l}\text { Toxicity } \\
\text { Index } \\
\end{array}$ & $\begin{array}{l}\text { Relative } \\
\text { Toxicity } \\
\text { Index } \\
\end{array}$ \\
\hline $\begin{array}{l}\text { Fission Product } \\
\text { Inventory per ton } \\
\text { of fuel, Lattice }\end{array}$ & $1.32 \times 10^{8}$ & $3.02 \times 10^{16}$ & - \\
\hline $\begin{array}{l}\text { Actinide Inventory } \\
\text { per ton of fuel, } \\
\text { Lattice }\end{array}$ & $3.67 \times 10^{7}$ & $2.87 \times 10^{16}$ & - \\
\hline $\begin{array}{l}\text { Fission Product } \\
\text { Inventory per ton } \\
\text { of fuel, Convertor }\end{array}$ & $i .27 \times 10^{7}$ & $2.86 \times 10^{15}$ & - \\
\hline $\begin{array}{l}\text { Actinide Inventory } \\
\text { per ton of fuel. } \\
\text { Convertor }\end{array}$ & $4.71 \times 10^{6}$ & $6.67 \times 10^{16}$ & - \\
\hline $\begin{array}{l}\text { Fission Product } \\
\text { Inventory, Lattice }\end{array}$ & $9.33 \times 10^{9}$ & $2.25 \times 10^{18}$ & 0.146 \\
\hline $\begin{array}{l}\text { Actinide Inventory, } \\
\text { Lattice }\end{array}$ & $2.73 \times 10^{9}$ & $2.14 \times 10^{18}$ & 0.140 \\
\hline $\begin{array}{l}\text { Fission Product } \\
\text { Inventory, Convertor }\end{array}$ & $1.99 \times 10^{9}$ & $4.49 \times 10^{17}$ & 0.029 \\
\hline $\begin{array}{l}\text { Actinide Inventory, } \\
\text { Convertor }\end{array}$ & $7.39 \times 10^{8}$ & $1.05 \times 10^{19}$ & 0.685 \\
\hline $\begin{array}{l}\text { Total Fission } \\
\text { Product Inventory }\end{array}$ & $1.18 \times 10^{10}$ & $2.70 \times 10^{18}$ & 0.176 \\
\hline $\begin{array}{l}\text { Total Actinide } \\
\text { Inventory }\end{array}$ & $3.47 \times 10^{9}$ & $1.26 \times 10^{19}$ & 0.8295 \\
\hline $\begin{array}{l}\text { Total Tritium } \\
\text { Inventory }\end{array}$ & $6.65 \times 10^{6}$ & $3.33 \times 10^{13}$ & 0.000002 \\
\hline Total Inventory & $1.53 \times 10^{10}$ & $1.53 \times 10^{19}$ & 1.0 \\
\hline
\end{tabular}

a. Based on normalizing total to unity. 


\section{RADIOACTIVE AFTERHEAT}

One of the results of the many calculations performed to derive the radioactive material inventory of the mirror hybrid reactor was information on the source of radioactive afterheat from the decaying fission products. This information is useful in any post accident analysis which might be performed on the mirror hybrid reactor concept.

Figure 4.1 summarizes the calculations of radioactive afterheat performed in this analysis. It is a plot of lattice power from decay of the radioactive inventory in $\mathrm{W} / \mathrm{cm}^{3}$ versus cooling time in days following reactor shutdown. The above information is shown on this figure for several different exposure times ranging from 0.1 year to 3 years, all at a lattice operating power density of $3.2 \mathrm{~W} / \mathrm{cm}^{3}$. In addition, one curve is supplied for the afterheat following one year's operation at $4.3 \mathrm{~W} / \mathrm{cm}^{3}$.

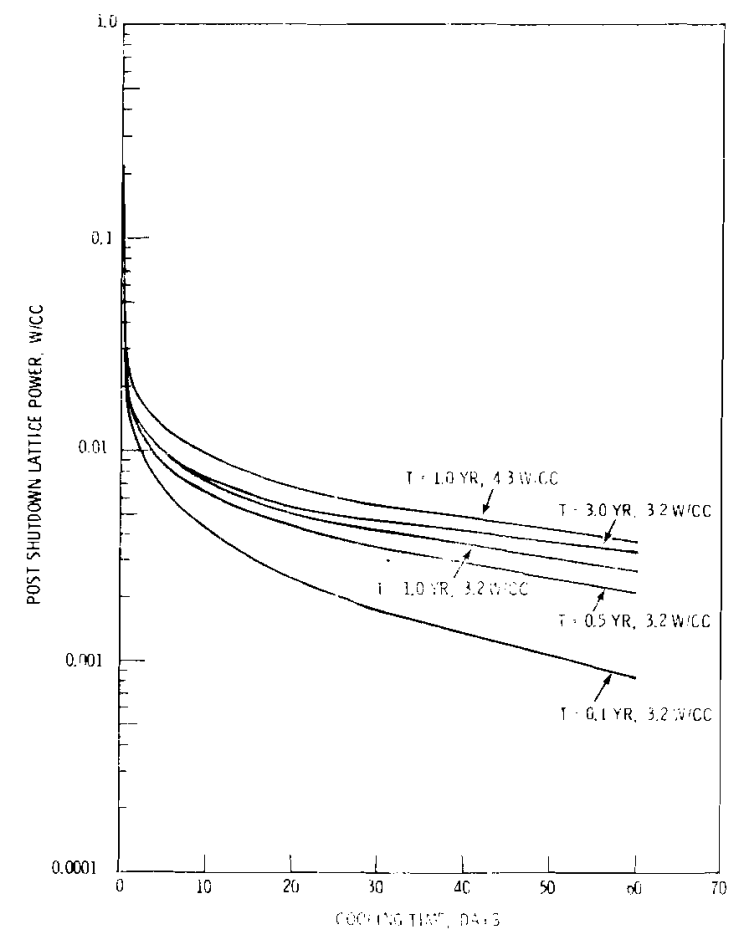

FIGURE 4.1 Radioactive Afterheat of Mirror Hybrid Reactor 
Figure 4.1 is useful in two respects. First of a11, it gives credible data for evaluation of shutdown heat levels in the mirror hybrid reactor. It also demonstrates that the radioactive inventory heat load associated with the hybrid blanket is only a mild function of fuel exposure. That is, most of the source seems to be created in the first month or so of operation. In addition, the heat source appears to be a linear function of the operating power density of the blanket. 


\section{AREAS OF FUTURE DEVELOPMENT}

As a result of the analysis which has been performed to date, a number of areas needing further development have been identified. These items are listed and discussed below. They constitute a possible second stage of development for the mirror hybrid reactor.

In the area of immediately needed future neutronics studies, four areas need to be examined. They are:

- Source Spectrum Effects

- Graded Fissile Enrichment

- Effect of Nuclear Improvements, (e.g., ENDF/B-IV), on Design Parameters

- Time Dependent Burnup Behavior

It can be shown that an injected reactor, such as the one described here, has a D-T neutron output source with a significant spread in energy. Preliminary analysis shows that neutron energies up to $17 \mathrm{MeV}$ need to be considered for a $100 \mathrm{keV}$ injection energy.

The power profile in the fission lattice of this design has a relatively high ratio of maximum to average power. Graded enrichment calculations need to be performed in order to determine if better spatial power distributions can be achieved.

The ${ }^{238} \mathrm{U}$ cross section sets used in the calculations reported here have been derived utilizing an inadequate description of the secondary neutron spectrum. The description comes from ENDF/B-III. Calculations utilizing more recent data would show that the convertor is more reactive than was reported here.

The rate of plutonium production as a function of time and the isotopic content of the bred plutonium as a function of time must be calculated in order to assess the time dependent reactivity of the design. The buildup of neutronic poisons, such as fission products, must also be included in the analysis of time dependent burnup behavior. 
Some supplemental neutronics analyses should be performed. Some recent calculations indicate that there is some advantage to specifying a thicker inner breeder region at the expense of the outer breeder region. This possibility needs to be investigated. In addition, a simple neutronics integral experiment that would confirm the neutronic properties of the blanket could be done to narrow the uncertainties in blanket performance deduced from calculational models.

Certain engineering analyses need to be performed on this design. The helium coolant operates at a pressure of 20 atmospheres. The plasma chamber is a near vacuum and the vacuum wall has been specified as being $1 \%$ of the total convertor volume region with an additional $6 \%$ of the convertor being structural material. The material specified is stainless steel. These structural percentages were selected based on neutronics and thermal hydraulics analysis. A structural analysis needs to be performed in order to assess the design and performance characteristics of the vacuum wall region. Because this design could result in the need for more structural material, additional neutronic and thermal hydraulics analyses may also have to be performed subsequent to this analysis.

The mirror hybrid design has been developed to point where a preliminary economic analysis could be performed. The cost of the fissile blanket can be rather accurately estimated because it is based on existing fission technology. Several preliminary economic analyses have been performed on mirror reactor designs with similar characteristics to the one specified here. Thus, the base information required to evaluate the higher cost of the blanket versus the benefit of the higher power output of the device can be evaluated. Additional possible economic advantages which result from more modest plasma physics requirements can also be evaluated. 
BNWL-1835

\section{REFERENCES}

1. B. R. Leonard, Jr., "A Review of Fusion-Fission (Hybrid) Concepts," Nuc1. Tech., vol. 20, pp 161-178, December 1973.

2. W. C. Wolkenhauer, B. R. Leonard, Jr., A. M. Sutey, PNL; R. W. Moir, LLL; "Conceptual Design of a Fusion-Fission Hybrid Reactor Based on a Mirror Fusion Reactor with a Gas Cooled Fission Blanket," BNWL-SA4865, First ANS Topical Conference on Fusion Reactor Technology, Apri1 1974.

3. W. C. Wolkenhauer, C. W. Stewart, PNL; R. W. Werner, J. D. Lee, LLL; "Some Safety Considerations of Hybrid Reactors in Comparison with Fission and Fusion Reactors," BNWL-SA-4988, First ANS Topical Conference on Fusion Reactor Technology, April 1974.

4. W. C. Wolkenhauer, B. R. Leonard, Jr., "Advances in the Development of the Mirror-Hybrid (Fusion-Fission) Reactor, BNWL-SA-4961, May 1974.

5. R. W. Werner, G. A. Carlson, J. Hovingh, J. D. Lee and M. A. Peterson, "Progress Report No. 1 on the Design Considerations for a Low-Power Experimental Mirror Fusion Reactor," Symposium on the Technology of Controlled Thermonuclear Fusion Experiments and the Engineering Aspects of Fusion Reactors, Austin, Texas, November 1972.

6. R. W. Moir and C. E. Taylor, "Magnets for Open-Ended Fusion Reactors," Proc. of the Texas Symposium on the Technology of Controlled Thermonuclear Fusion Experiments and the Engineering Aspects of Fusion Reactors, CONF 721111, pp. 853-883, 1974.

7. M. E. Rensink, Jr., J. Killeen, and A. A. Mirin, Some Recent Computational Results on Mirror Confinement, Lawrence Livermore Laboratory Report UC ID-16459, 1974.

8. R. W. Moir, "Conceptual Design Considerations for D-T Mirror Reactors with and without a Fission Blanket," First ANS Topical Conference on Fusion Reactor Technology, Apri1 1974.

9. A. H. Futch, Jr., J. D. Holdren, J. Killeen and A. A. Mirin, Plasma Physics, vol. 14, 211, 1972.

10. J. Hovingh and R. W. Moir, Efficiency of Injection of High Energy Neutral Beams into Thermonuclear Reactors, Lawrence Livermore Laboratory Report UCRL-51419, 1973.

11. L. D. Hansborough, R. W. Werner, "A Modular Fission-Fusion Hybrid Blanket," First ANS Topical Conference on Fusion Reactor Technology, April 1974. 
12. Public Service Company of Colorado, "Final Safety Analysis Report for the Ft. St. Vrain Nuclear Generating Station," vol. 2, Denver, Colorado, April 1973.

13. C. L. Bennett, GRANIT: A Code for Calculating Position-Dependent Thermal Neutron Spectra in Doubly Heterogeneous Systems by the Integral Transport Method, BNWL-1634, November 1971

14. C. R. Richey, EGGNIT: A Multigroup Cross-Section Code, BNWL-1203, November 1967.

15. B. R. Leonard, Jr., and W. C. Wolkenhauer, "Fusion-Fission Hybrids: A Subcritical Thermal Fission Lattice for a D-T Fusion Reactor," Symposium on the Technology of Controlled Thermonuclear Fusion Experiments and the Engineering Aspects of Fusion Reactors, CONF-721111, 918-930, Apri1 1974.

16. J. W. Weale, H. Goodfellow, M. H. McTaggart, and M. L. Mullender, "Measurement of the Reaction Rate Distribution Produced by a Source of 14-MeV Neutrons at the Center of a Uranium Metal Pile," Reactor Science and Technology, vol. 14, pp. 91-99, 1961.

17. Y. Seki, K. Sako, K. Tanaka, T. Hirasks, "Tritium Breeding in Ceramic Lithium-Compound Blanket," First Topical Conference on the Technology of Controlled Nuclear Fusion, Apri1 1974.

18. W. W. Engle, Jr., A Users Manual for ANISN, A One-Dimensional Discrete Ordinates Transport Code with Anisotropic Scattering, $\mathrm{K}-1693,1967$.

19. Frank Krieth, Principles of Heat Transfer, International Textbook Company, Scranton, Pa., 1965.

20. Philadelphia Electric Company, "Preliminary Safety Analysis Report for the Fulton Generating Station - Units 1 and 2,"November 16, 1973.

21. R. W. Werner, Lawrence Livermore Laboratory, Private Files and Communications, 1973.

22. M. J. Be11, ORIGEN - The ORNL Isotope Generation and Depletion Code, ORNL-4628, May 1973.

23. Code of Federal Regulations, 10 CFR 20, Appendix B, U. S. Government Printing Office, Washìngton, D.C., January 1972. 
BNWL -1835

APPENDIX A 
APPENDIX A

\section{CALCULATIONAL MODELS}

During the course of performing the analyses reported here, a number of calculational models were formulated and used. In general, these models consisted of computer codes developed previously by various authors which were modified and/or linked together in order to solve the problems of interest in this work. The calculational models thus developed and used in this analysis are described here.

The unit cell neutronic parametric studies were performed with the EGGNIT $^{(1)}$ and GRANIT ${ }^{(2)}$ codes. The EGGNIT code, a major revision of the GAMTEC-II ${ }^{(3)}$ code, was developed to generate multigroup constants for neutron diffusion and transport calculations. Most of the revisions were made in the resonance theory treatment where the added Nordheim numerical integration method ${ }^{(4)}$ permits treating absorbers and admixed scatterers exactly. An iterative technique extends Nordheim's method to multiregion geometries. Other features of EGGNIT include allowance for interference absorption due to resonances being close to each other in energy, resonance-potential interference scattering, and Dancoff shielding for either square or hexagonal lattices by the DASQHE ${ }^{(5)}$ program. The GRANIT code is a special version of the THERMOS ${ }^{(6)}$ code. The code explicitly computes position-dependent diluent and particle spectra in granular regions, in addition to the position-dependent spectra in homogeneous regions, for doubly heterogeneous systems by using the well known THERMOS method with a redistributed first flight collision matrix. The combination of EGGNIT and GRANIT was developed in part to accurately calculate the neutronic behavior of particle fuels in a graphite moderator at operating conditions. As such, they constitute a useful set of codes for analysis of the hybrid blanket studied here.

The ANISN $(7)$ code was used to perform the neutronics analysis of the total blanket. ANISN solves the one dimensional Boltzmann transport 
equation for slab, cylindrical or spherical geometry. As a second calculation, the detailed flux generated as the solution to the Boltzmann equation may be used to perform a group reduction of the cross sections. A P-3, S-8 approximation was used in all analyses reported here.

Data used in the analysis were obtained from the ENDF/B-III ${ }^{(8)}$ 1ibrary. In general, the ENDF/B-III data were processed by means of the ETOG $^{(9)}$ and FLANGE $(10)$ codes into multigroup constants. For the data used in the ANISN code, the data was first processed into 100-energy group format and then collapsed with the ANISN code into 27-energy groups assuming a neutron spectrum for an infinite medium of graphite.

Two important physical effects needed to be accounted for in order to complete the data development for the ANISN code. Both the selfshielding effect of particle fuel assembled in discrete fuel rods and the temperature effects of operation at design temperatures need to be accounted for. In order to accomplish this, the reaction cross sections for the 27-energy group P-3, S-8 cross-section set derived from the AllISIN collapse were modified. The technique used involved calculations at temperature of the material of interest with EGGNIT and GRANIT and then substitution of the capture, fission, and total absorption cross sections from EGGNIT and GRANIT into the P-3, S-8, 27-group set. Corrections to the total cross section were necessary in order that the final crosssection set balanced. While the above procedure is straightforward in principle, the combination of a mismatch in energy group structure between the ANISN 27-energy group set on the one hand and EGGNIT and GRANIT on the other, combined with the volume of data to be handled, resulted in the need to develop an automated formalism for the procedure. Table A.1 lists the analytic transformations developed for transfer of EGGNIT/GRANIT data into the 27-energy group format desired. (11) EGGNIT data were available in 22-energy groups and GRANIT data in 3-energy groups. The 27-energy group structure is given in Appendix B.

These transfer functions were used to develop P-3, S-8 27-energy group cross sections for every applicable reaction of pertinent isotopes 
BNWL-1835

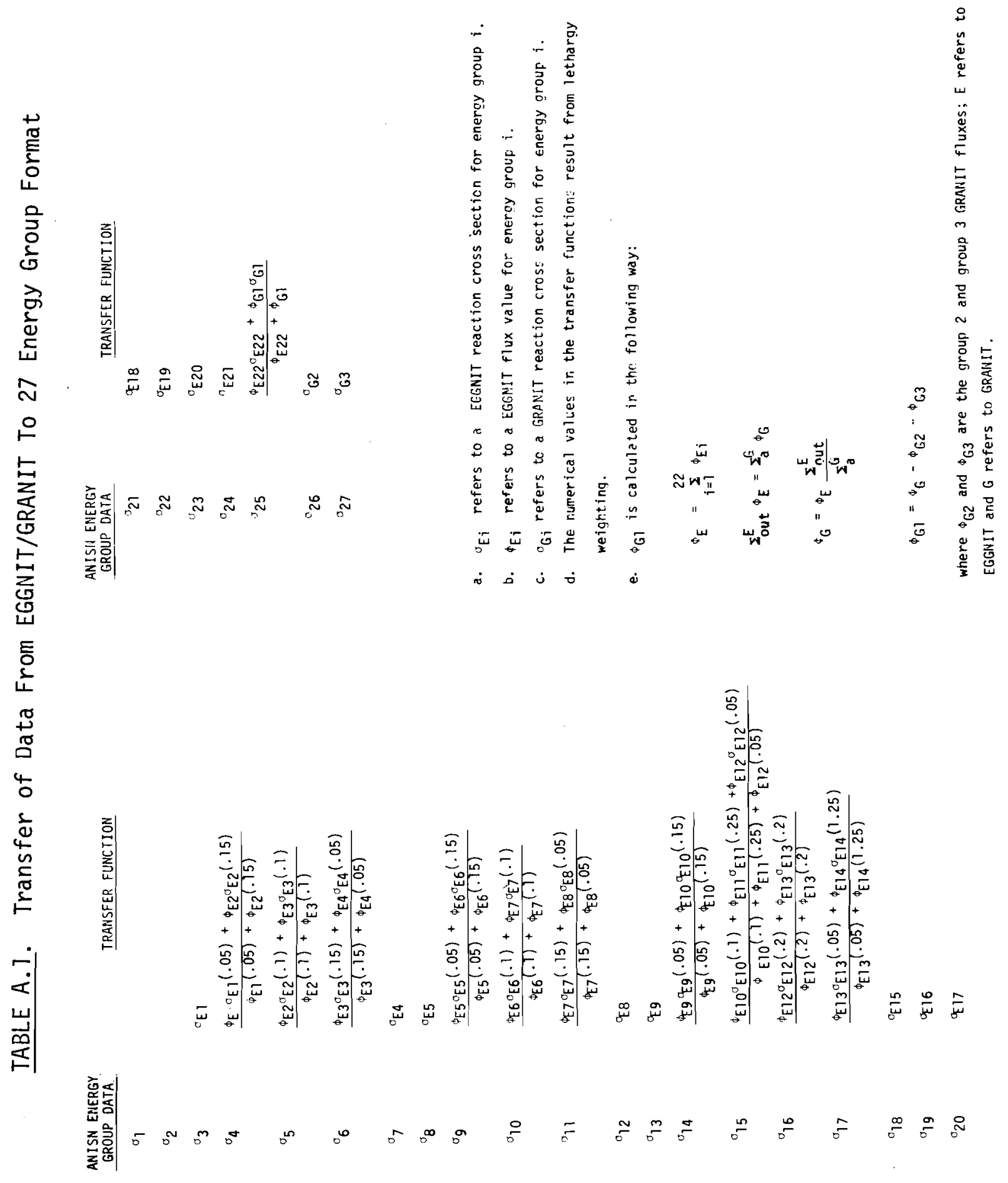


used in the analysis. In this way, spatial and temperature effects were included in the analysis.

Radioactive waste inventories for the hybrid were calculated using the ORIGEN ${ }^{(12)}$ code. ORIGEN is a point depletion code which solves the equations for radioactive growth and decay for large numbers of isotopes with arbitrary coupling. The code uses the matrix exponential method to solve coupled, linear, first-order ordinary differential equations with constant coefficients. ORIGEN computes the compositions and radioactivity of fission products, cladding materials, and fuel materials with the results available in alternate sets of units. For this application, modifications to the code were made in order that the eigenvalue and the fissile breeding ratio could be computed with time. A three energy group cross-section library was developed for the hybrid reactor for use in the ORIGEN code by means of spectrum averaging of the 27-energy group ANISN cross sections over the blanket region.

The thermal hydraulics analysis was carried out with the TRUTH code, written specifically for this project. TRUTH is a digital computer program for steady state and transient thermal analysis of heat conducting systems. It computes heat transfer rates and temperatures throughout any arbitrary collection of discrete interconnected subvolumes (nodes) which are described by the user to represent a physical system. The mathematical model consists of an energy balance on each node which considers the heat capacity and heat transfer along an arbitrary number of paths to adjacent nodes. Different thermal properties may be assigned to each node, but temperature dependence of properties is not considered at this time.

Heat may be transferred by radiation, forced or free convection, or conduction. Incompressible fluid flow at specified mass flow rates may also be considered. The equations of the mathematical model are solved by using a fully explicit finite difference scheme with an internally computed time step. Initial nodal temperatures and volumes must be specified by the user in addition to the conduction resistance and heat transfer area of each connection. 
BNWL-1835

\section{REFERENCES}

1. C. R. Richey, EGGNIT: A Multigroup Cross Section Code, BNWL-1203, Pacific Northwest Laboratories, Richland, Washington, November 1967.

2. C. L. Bennett, GRANIT: A Code for Calculating Position Dependent Thermal Neutron Spectra in Doubly Heterogeneous Systems by the Integral Transport Method, BNWL-1634, Pacific Northwest Laboratories, Richland, Washington, November 1971.

3. L. L. Carter, C. R. Richey, and C. E. Hughey, GAMTEC-II: A Code for Generating Consistent Multigroup Constants Utilized in Diffusion and Transport Theory Calculations; BNWL-35, Pacific Northwest Laboratories, Richland, Washington, March 1965.

4. F. T. Adler, G. W. Hinman, and L. W. Nordheim, "The Quantitative Evaluation of Resonance Integrals," Paper No. p/1988, Proceedings of the Second United Nations International Conference on the Peaceful Uses of Atomic Energy, United Nations, Geneva, vol. 16, pp. 155-171, 1958.

5. T. M. Traver, Users Manual for Program DASQHE, BNWL-CC-2274, Pacific Northwest Laboratories, Richland, Washington, September 15, 1969.

6. H. C. Honeck, THERMOS, A Thermalization Transport Theory Code for Reactor Lattice Calculations, BNL-5826, Brookhaven National Laboratory, Upton, New York, September 1961.

7. W. W. Engle, Jr., A Users Manual for ANISN, A One-Dimensional Discrete Ordinates Transport Code with Anisotropic Scattering, K-1693, Oak Ridge National Laboratory, 1967.

8. H. C. Honeck, ENDF/B, Specifications for an Evaluated Nuclear Data File for Reactor Applications, BNL-50066, USAEC, 1966.

9. D. E. Kusner, R. A. Danne1s, and J. Kel 1man, ETOG-I, A Fortran IV Program to Process Data from the ENDF/B file to the MUFT, GAM, and ANISN Formats, WCAP-3845-1, ENDF-114, December 1969.

10. H. C. Honeck and D. R. Finch, FLANGE II, A Code to Process Thermal Neutron Data from an ENDF/B Tape, DP-1278 (ENDF-152), Savannah River Laboratory, 1971.

11. D. F. Newman, Private Communication, Battelle-Northwest, January 1974 .

12. M. J. Be11, ORIGEN - the ORNL Isotope Generation and Depleted Code, ORNL-4628, Oak Ridge National Laboratory, May 1973.

13. B. H. Duane, Time-Variant Isotopic Transmutation GE-HL Program ALCHEMY, HW-80020, Hanford Laboratories, 1963. 
14. W. C. Wolkenhauer, B. R. Leonard, Jr., A. M. Sutey, PNL, and R. W. Moir, LLL, "Conceptual Design of a Mirror Fusion Reactor with a Subcritical Gas Cooled Fission Blanket, "BNWL-SA-4865, First Topical Meeting on the Technology of Controlled Nuclear Fusion, San Diego, California, April 1974. 
BNWL -1835

APPENDIX B 
BNWL - 1835

APPENDIX B

\section{COMPARISON OF CALCULATED AND MEASURED REACTION RATE DISTR IBUTIONS IN A URANIUM METAL ASSEMBLY WITH A CENTRAL 14-MeV NEUTRON SOURCE}

Analytical neutronic design studies for fusion-fission (hybrid) reactors have been based on calculational models commonly employed in the design of fission reactors. (1) Since neutrons are introduced into a critical fission reactor at an average energy around 2-MeV, the conclusions reached about the adequacy of calculational models from correlations with critical fission reactor experiments should only be extrapolated with consideration that DT fusion reactors introduce neutrons at $14-\mathrm{MeV}$.

In 1961 Weale, et al ${ }^{(2)}$ of the U. K. Atomic Weapons Research Establishment at Aldermaston, U. K., published the results of their experimental investigation of reactions induced by a source of 14-MeV neutrons at the center of a large uranium metal assembly. These results provided a useful reference for checking calculational models and nuclear data that will be used for the neutronic design of a fast neutron convertor region in the blanket of a deuterium-tritium fueled fusion-fission hybrid reactor.

\section{A. DESCRIPTION OF THE EXPERIMENT}

The assembly ${ }^{(2)}$ consisted of a cylindrical uranium metal pile 42 inches high and 39 inches in diameter with a source of 14-MeV neutrons in the center. This assembly is large enough to absorb virtually all of the source neutrons and to establish a flux of secondary neutrons which approaches their equilibrium energy spectrum. The reaction rate distributions for ${ }^{235} \mathrm{U}(n, f),{ }^{238} \mathrm{U}(n, f),{ }^{238} \mathrm{U}(n, \gamma),{ }^{239} \mathrm{Pu}(n, f)$, and ${ }^{63} \mathrm{Cu}$ $(n, 2 n)$ were measured.

Natural uranium meta 1 rods 42 inches 1 ong and 1.150 inches in diameter were mounted vertically to form a triangular lattice with a 1.175-in. 
pitch. The average density of the arrangement was $16.3 \mathrm{~g} / \mathrm{cm}^{3}, i . e ., 87 \%$ of the density of the uranium metal. The total weight of the assembly was nearly 20 tons. The center of the assembly was 6 feet above the concrete floor and except for the steel framework there was no other reflecting or moderating material within 8 feet in any direction.

The source of neutrons was a thick $\mathrm{Zr}-\mathrm{T}$ target bombarded by 200-keV deuterons from a Cockcroft-Walton accelerator. Access for the drift tube was provided by a channel 2-3/4 inches deep and 7/8 inch wide and the source was thus located in the central rod position with its center 22 inches from the top surface of the pile. The steady state source strength was $5 \times 10^{9}$ neutrons/sec from the D-T reaction. The content of $D-D$ neutrons from absorbed gas was estimated as not more than $2 \%$.

The distributions of fission rates in ${ }^{239} \mathrm{Pu}, 235 \mathrm{U}$, and $238 \mathrm{U}$ were measured using cylindrical fission chambers. The counters were filled with $0.82 \mathrm{mg}$ of plutonium $(98 \% 239 \mathrm{Pu}, 2 \% 240 \mathrm{Pu}), 91.1 \mathrm{mg}$ of uranium (93\% $235 \mathrm{U}, 5.2 \% 238 \mathrm{U}, 1.8 \% 234 \mathrm{U})$, and $104.1 \mathrm{mg}$ of uranium $(99.98 \% 238 \mathrm{U}, 0.02 \%$ $235 \mathrm{U})$, respectively. Corrections for self-shielding were assumed to be negligible for these chambers.

The capture rate distribution in $238 \mathrm{U}$ and the $(n, 2 n)$ reaction distribution in ${ }^{63} \mathrm{Cu}$ were measured using foils of natural uranium metal and copper metal, respectively. The $238 \mathrm{U}$ capture rate distribution was determined by counting the ${ }^{239} \mathrm{~Np}$ that was chemically separated from the uranium foils after a 24-hr irradiation.

\section{B. DESCRIPTION OF CALCULATIONAL METHODS}

In the present study, the neutronic behavior of the natural uranium metal assembly was calculated using the ANISN code ${ }^{(3)}$ in the $\mathrm{P}_{3}, \mathrm{~S}_{8}$ approximation with a 27-energy-group structure, 1isted in Table B.1, that was used in many previous fusion-fission hybrid reactor calculations at PIVL. (4) Assuming that the reaction rate distributions measured in the horizontal plane of a cylinder are the same as those which would be observed in a sphere of the same radius as the cylinder, (2) a 39-in. diameter bare spherical assembly was modeled using 80 spatial mesh intervals. The 
14-MeV neutron source was placed entirely in the central spatial mesh interval $(0$ to $0.32 \mathrm{~cm}$ ) and the highest energy group (14.9 to $12.2 \mathrm{MeV}$ ). The calculations were based on ENDF/B-III data which were obtained from ORNL as 100 -group cross sections ${ }^{(5)}$ and collapsed into the 27 -group structure listed in Table B.1. Since the collapsed ENDF/B-III cross sections were obtained for the condition of infinite dilution, corrections have to be made to account for self-shielding. To account for self-shielding, absorption and fission cross section for ${ }^{238} \mathrm{U}$ and $235 \mathrm{~J}$ were generated using the EGGNIT ${ }^{(6)}$ and GRANIT ${ }^{(7)}$ codes. For $238 \mathrm{U}$ and $235 \mathrm{U}$, the total cross section for each energy group and the transfer matrix were corrected to properly account for $(n, 2 n)$ and $(n, 3 n)$ reactions. (8)

\section{COMPARISON OF CALCULATED RESULTS TO EXPERIMENTAL DATA}

The calculated reaction rate distributions for ${ }^{63} \mathrm{Cu}(n, 2 n),{ }^{238} \mathrm{U}$ $(n, f),{ }^{238} U(n, \gamma), 235 U(n, f)$, and ${ }^{239} \mathrm{Pu}(n, f)$ are compared to the measured data in Figures $B .1$ through $B .5$, respectively. Since ${ }^{63} \mathrm{Cu}$ $(n, 2 n)$ reaction has a threshold at $11.5-\mathrm{MeV}$, the distribution of this reaction rate, shown in Figure $B .1$, is a good indication of the penetration of the near 14-MeV neutrons from the central source into the surrounding uranium metal. Both the calculation and experiment show nearly a single exponential spatial dependence of the ${ }^{63} \mathrm{Cu}(n, 2 n)$ reaction rate. However, the slope of the calculated results is about $15 \%$ more negative than the measured data, i.e., the calculation underestimates the distance that neutrons near $14-\mathrm{MeV}$ penetrate into the uranium metal. The dimensions of the assembly are sufficiently large that the leakage of $14-\mathrm{MeV}$ neutrons from the assembly exterior is negligible, as shown in Figure B.1. 
TABLE B.1 27-Group Structure for ANISN Calculations

\begin{tabular}{|c|c|c|c|}
\hline & Upper Energy & & \\
\hline Group & $\frac{e, e v}{e}$ & $\Delta u$ & u \\
\hline 1 & $14.92 \times 10^{6}$ & 0.2 & -0.4 \\
\hline 2 & $12.21 \times 10^{6}$ & 0.2 & -0.2 \\
\hline 3 & $10.00 \times 10^{6}$ & 0.2 & 0.0 \\
\hline 4 & $8.19 \times 10^{6}$ & 0.2 & 0.2 \\
\hline 5 & $6.70 \times 10^{6}$ & 0.2 & 0.4 \\
\hline 6 & $5.49 \times 10^{6}$ & 0.2 & 0.6 \\
\hline 7 & $4.49 \times 10^{6}$ & 0.2 & 0.8 \\
\hline 8 & $3.68 \times 10^{6}$ & 0.2 & 1.0 \\
\hline 9 & $3.01 \times 10^{6}$ & 0.2 & 1.2 \\
\hline 10 & $2.47 \times 10^{6}$ & 0.2 & 1.4 \\
\hline 11 & $2.02 \times 10^{6}$ & 0.2 & 1.6 \\
\hline 12 & $1.65 \times 10^{6}$ & 0.2 & 1.8 \\
\hline 13 & $1.35 \times 10^{6}$ & 0.2 & 2.0 \\
\hline 14 & $1.11 \times 10^{6}$ & 0.2 & 2.2 \\
\hline 15 & $0.907 \times 10^{6}$ & 0.4 & 2.4 \\
\hline 16 & $0.608 \times 10^{6}$ & 0.4 & 2.8 \\
\hline 17 & $0.408 \times 10^{6}$ & 1.3 & 3.2 \\
\hline 18 & $0.111 \times 10^{6}$ & 2.0 & 4.5 \\
\hline 19 & $15.03 \times 10^{3}$ & 1.5 & 6.5 \\
\hline 20 & $3.35 \times 10^{3}$ & 1.75 & 8.0 \\
\hline 21 & $0.583 \times 10^{3}$ & 1.75 & 9.75 \\
\hline 22 & $0.101 \times 10^{3}$ & 1.25 & 11.50 \\
\hline 23 & 29.02 & 1.0 & 12.75 \\
\hline 24 & 10.68 & 1.25 & 13.75 \\
\hline 25 & 3.06 & 0.96 & 15.0 \\
\hline 26 & 1.166 & 0.63 & 15.96 \\
\hline 27 & 0.625 & $\infty$ & 16.59 \\
\hline
\end{tabular}


BNWL -1835

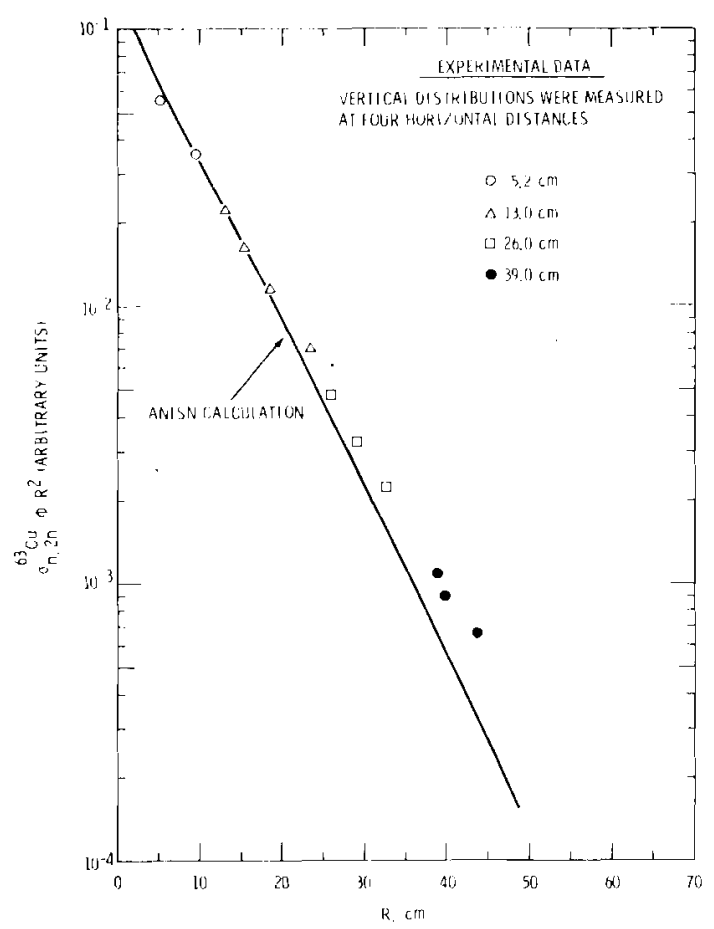

FIGURE B.1 Distribution of ${ }^{63} \mathrm{Cu}(n, 2 n)$ Reaction Rate

The secondary neutrons produced by $(n, 3 n),(n, 2 n)$, and $(n, f)$ reactions as a result of the $14-\mathrm{MeV}$ neutron source have a somewhat degraded fission spectrum. The average energy of these neutrons declines with distance from the source until equilibrium is established between those processes which tend to harden the spectrum (fission at a11 energies and preferential capture of lower energy neutrons) and those which tend to soften the spectrum (inelastic collisions and preferential leakage of higher energy neutrons). Experimental data indicate that this equilibrium is established at distances greater than $35 \mathrm{~cm}$ from the source. The calculations underestimate this distance by a few centimeters.

The distributions for the $238 U(n, f), 238 U(n, \gamma), 235 U(n, f)$ and $239 \mathrm{Pu}(n, f)$ reactions are all dominated by the distribution of the secondary neutron flux. Comparison should only be made between the 


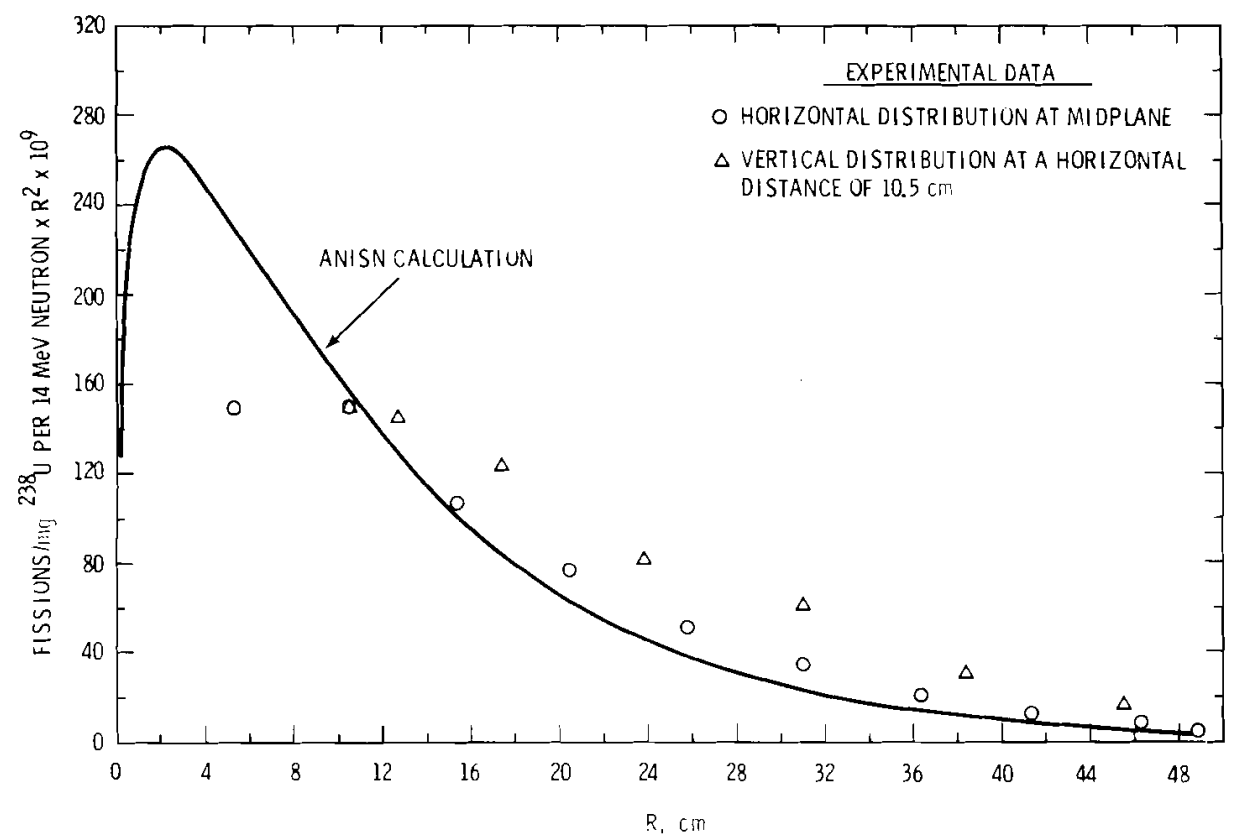

\section{FIGURE B.2 Distribution of $238 \mathrm{U}$ Fission Rate}

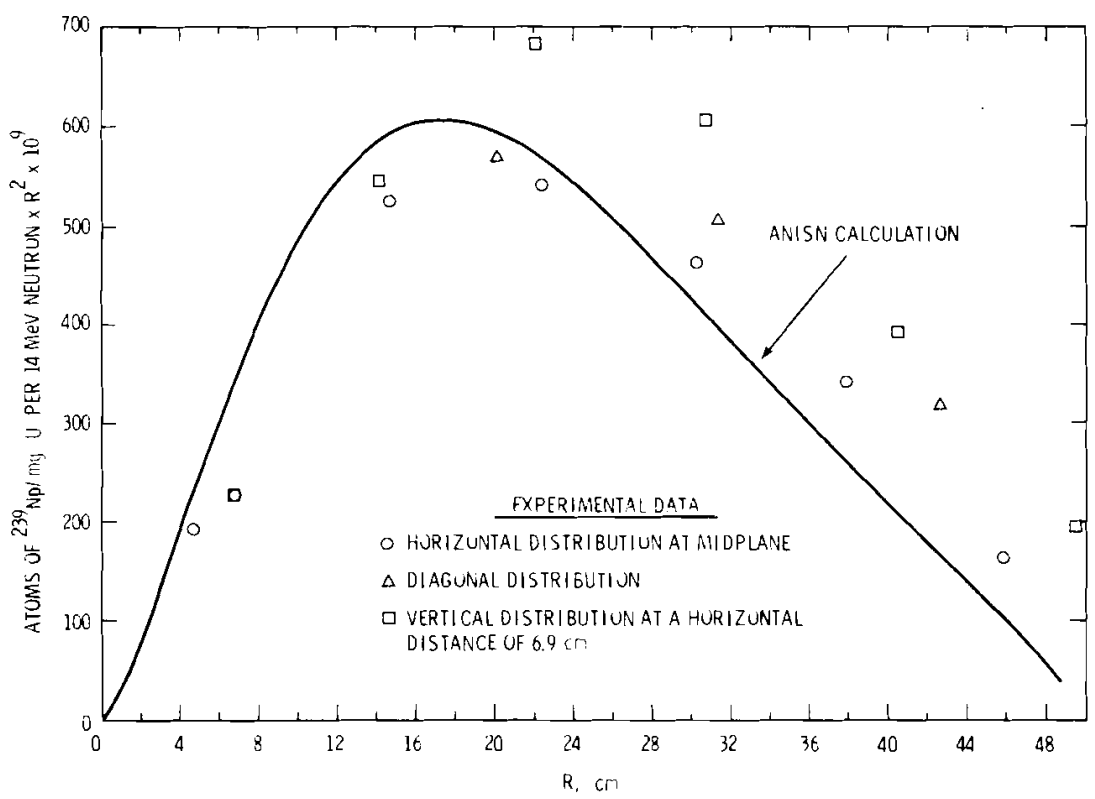

FIGURE B.3 Distribution of $238 \mathrm{U}$ Neutron Capture Rate 


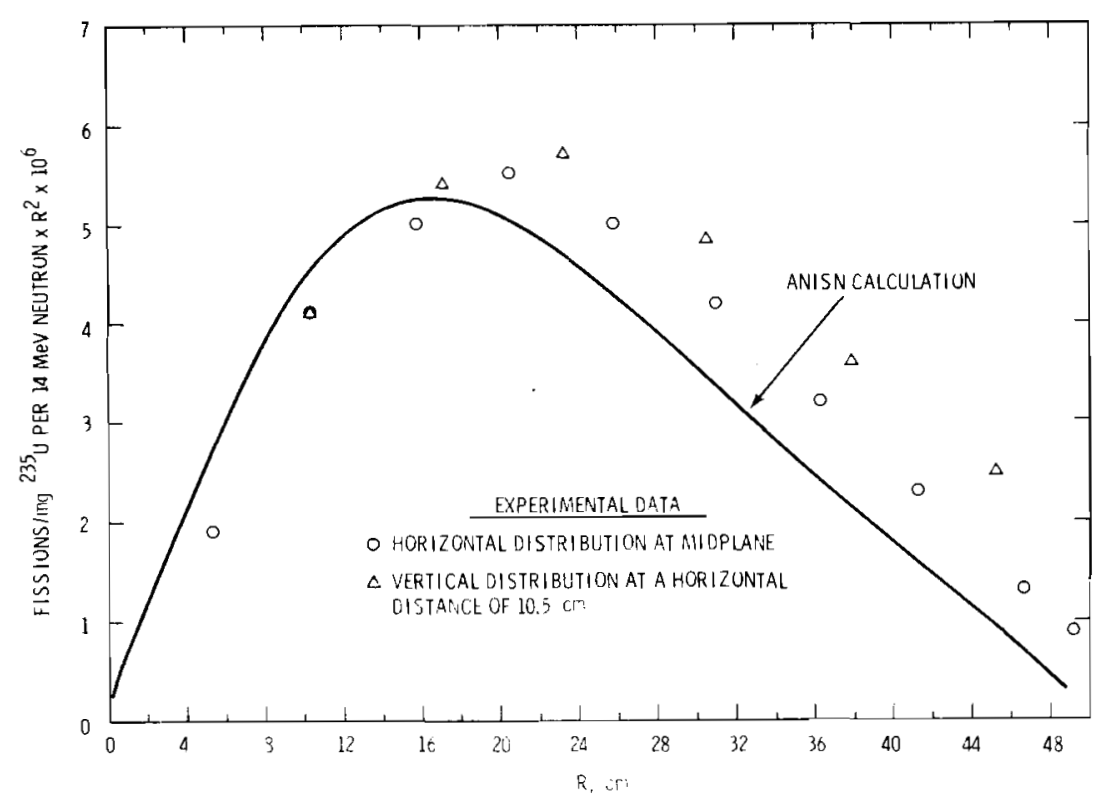

FIGURE B.4 Distribution of $235 \mathrm{U}$ Fission Rate

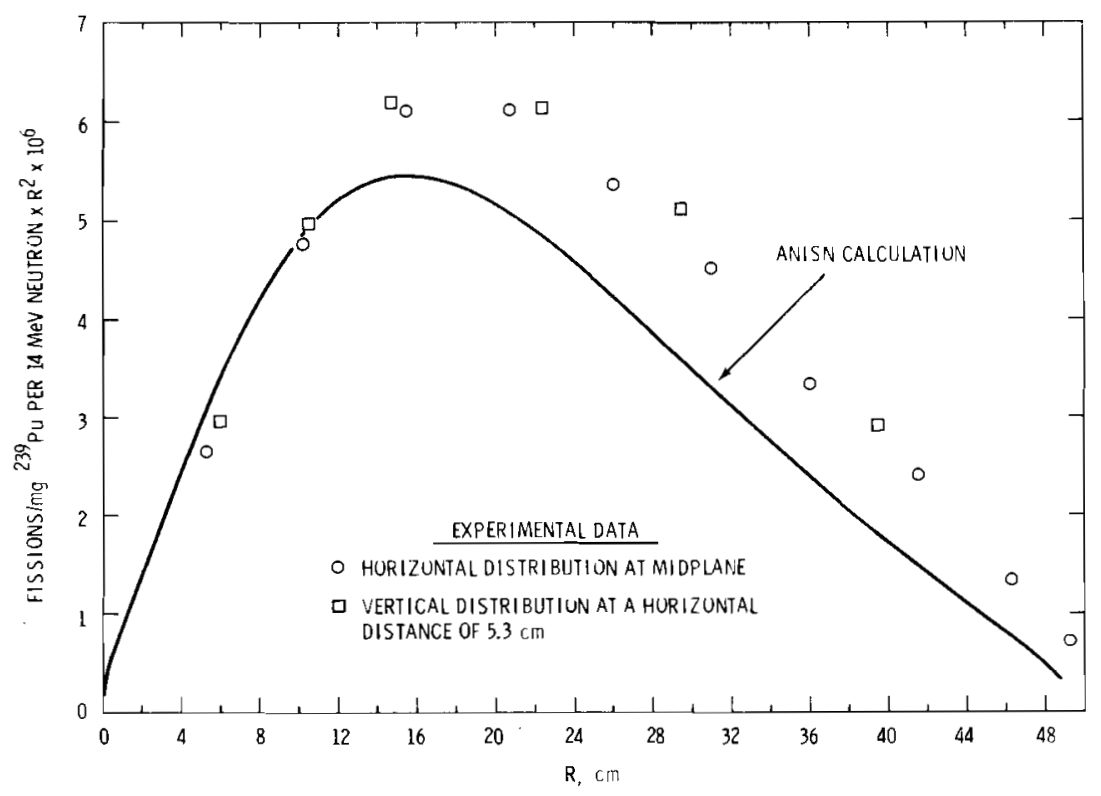

FIGURE B.5 Distribution of ${ }^{239} \mathrm{Pu}$ Fission Rate 
calculations and the data measured at the horizontal midplane, since the spherical model used in the calculations is a poor approximation for the vertical distribution in the cylindrical assembly. The calculations overestimate the reaction rates up to a radial distance of about $13 \mathrm{~cm}$ from the source. Beyond this distance the calculations tend to underestimate the reaction rates. The fractional error in the calculated distributions increases with distance beyond about $13 \mathrm{~cm}$ and approaches a value of 0.5 at the outer edge of the assembly. This fractional error is consistent with that observed for the ${ }^{63} \mathrm{Cu}(n, 2 n)$ reaction, and is the result of the calculational underestimate of the distance 14-MeV neutrons penetrate into the uranium assembly.

In order to check the consistency of the nuclear data with experiment, spatially averaged fission and capture reactions calculated for $235 \mathrm{~J}$ and $238 \mathrm{U}$ in the assembly were combined to derive the neutron gain per source neutron for comparison with the value Weale ${ }^{(2)}$, derived from the experimental data. The calculated value of 3.5 secondary neutrons per 14-MeV source neutron compares well with the experimental value of $3.7 \pm$ 0.2 .

CONCLUSIONS

A number of conclusions can be drawn from the comparison of calculated and measured reaction rates in the uranium assembly with a central 14-MeV neutron source.

- Calculations with ANISN in the S-8, P-3 approximation underpredict the penetration distance of $14-\mathrm{MeV}$ neutrons in uranium meta1.

- Reaction rates dominated by the flux of secondary neutrons are overpredicted at distances up to about $13 \mathrm{~cm}$ from the neutron source.

- At distances greater than $13 \mathrm{~cm}$ fron the neutron source, reaction rates dominated by the flux of secondary neutrons are underpredicted.

- The fractional error in the calculated distributions of reaction rates approaches a value of 0.5 at the outer edge of the assembly. 
- The calculated value of 3.5 secondary neutrons gained per source neutron, averaged over the entire assembly is in agreement with the experimental value of $3.7 \pm 0.2$.

The underprediction of the deep penetration of near 14-MeV neutrons is not unexpected. Howerton and MacGregor $(9)$ have compared experimentally measured time-of-flight neutron spectra for $238 \mathrm{U}$ spheres pulsed with 14-MeV neutrons $(10)$ with spectra calculated using the $238 \mathrm{U}$ ENDF/B-III MAT 1158 data file used in the present calculation. Howerton's comparisons clearly show that the ENDF/B description of the energies of 14-MeV neutrons inelastically scattered from ${ }^{238} \mathrm{U}$ is badly deficient. In ENDF/B-III, the secondary neutrons from inelastic scattering of $14-\mathrm{MeV}$ incident neutrons are described as a Maxwellian distribution in energy with an average energy of about $1.2 \mathrm{MeV}$ with an isotropic distribution in laboratory space. Although the angle and energy distributions of inelastically scattered incident $14-\mathrm{MeV}$ neutrons on $238 \mathrm{U}$ have not been measured, it is physically expected that most of the neutrons lose little energy in inelastic scattering at these energies and that most of the scattering is in the forward direction. Thus, a significant fraction of the neutrons inelastically scattered would not be removed from the two highest broad energy groups used in ANISN which contain the ${ }^{6} \mathrm{C} u(n, 2 n)$ reaction. This deficiency in the data files probably causes a significant portion of the underprediction of the penetration of near 14-MeV neutrons in the uranium assembly.

In a similar way, the ENDF/B-III description of the energy distribution of secondary neutrons from the $n, 2 n$. reaction on $238 \mathrm{U}$ probably greatly overpredicts the number of low-energy neutrons. The over prediction of the number of low-energy neutrons from inelastic and $n, 2 n$ reactions would also be expected to contribute significantly to the biases in observed angular distributions of the other measured reactions (Figures B.2 - B.5), i.e. the observed biases are in the expected directions. 
BNWL -1835

\section{REFERENCES}

1. B. R. Leonard, Jr., "A Review of Fusion-Fission (Hybrid) Concepts," Nuclear Technology, vol. 20, p. 161, 1973.

2. J. W. Weale, H. Goodfellow, M. H. McTaggart and M. L. Mullender, "Measurements of the Reaction Rate Distribution Produced by a Source of 14-MeV Neutrons at the Centre of a Uranium Metal Pile," Reactor Sci. Technol., vol. 14, p. 91, 1961.

3. W. W. Engle, Jr., A User's Manual for ANISN, K-1693, Union Carbide Corporation, Nuclear Division, Oak Ridge Gaseous Diffusion Plant, Oak Ridge, Tennessee, March 1967.

4. W. C. Wolkenhauer, B. R. Leonard, Jr., D. F. Newman and U. P. Jenquin, "Study of a Fission Blanket for a Mirror Confinement CTR," BNWL-1823 Pacific Northwest Laboratory Annual Report for 1973 on Control led Thermonuclear Reactor Technology, Battelle Pacific Northwest Laboratories, Richland, Washington, p. 13, April 1974.

5. "100 Group Neutron Cross-Section Data Based on ENDF/B," DLC-2D, RSIC Data Library Collection, Oak Ridge, Tenn.

6. C. R. Richey, EGGNIT: A Multigroup Cross-Section Code, BNWL-1203, Battelle Pacific Northwest Laboratories, Richland, Washington, November 1969.

7. C. L. Bennett, GRANIT: A Code for Calculating Position-Dependent Thermal Neutron Spectra in Doubly Heterogeneous Systems by the Integral Transport Method, BNWL-1634, Battelle Pacific Northwest Laboratories, Richland, Washington, December 1971.

8. B. F. Gore, "Cross-Section Manipulations for Computer Code ANISN," Battelle Pacific Northwest Memo to ANISN Users, March 5, 1973.

9. R. J. Howerton and M. H. MacGregor, Evaluated Neutron Reaction Data for Uranium 238, UCRL-51427, Lawrence Livermore Laboratory, July 1973.

10. C. Wong, et a1., UCRL-51144, Rev. 1, Addendum, Lawrence Livermore Laboratory, (to be published). 
BNWL -1835

APPENDIX C 


\section{APPENDIX C}

\section{PLANT SYSTEM DESIGN MODEL}

In order that a complete system design could be performed relating a11 of the important design parameters, a simple mathematical model of the reactor was developed. The mirror hybrid reactor is shown schematically in Figure C.1. The approach used in this development was suggested by Werner. (1)

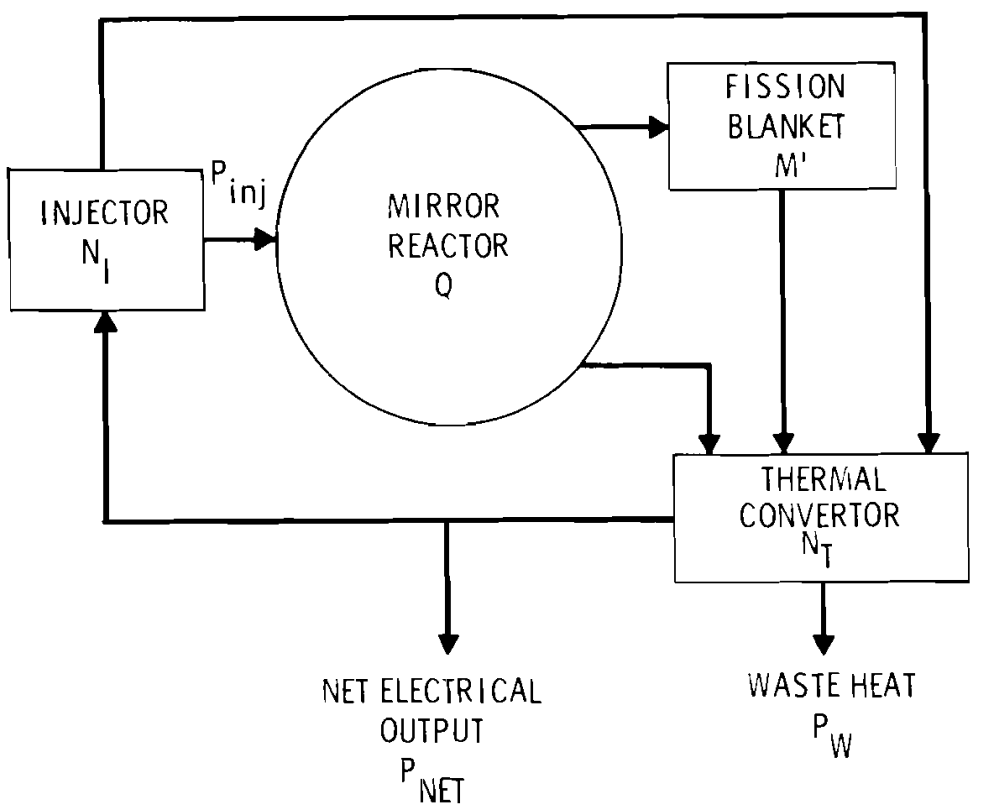

FIGURE C.1 Mirror Hybrid Schematic Diagram

Figure $C .1$ shows a mirror hybrid reactor with a plasma energy multiplication $Q$ coupled to a fissile blanket which multiplies the portion of $Q$ appearing as energetic neutrons by a factor $M$. The terms in the equations below are defined as:

$$
\begin{aligned}
& N_{T}=\text { Assumed efficiency of thermal/electric convertor } \\
& N_{I}=\text { Efficiency of ion injector }
\end{aligned}
$$




$$
\begin{aligned}
& N_{S}=\text { Efficiency of the entire system } \\
& P_{\text {inj }}=\text { Amount of power injected into the plasma } \\
& P_{\text {NET }}=\text { Net el ectrical output of the plant } \\
& P_{W}=\text { Waste heat output } \\
& P_{B}=\text { Total blanket power } \\
& P_{\text {FUS }}=\text { Total fusion power }
\end{aligned}
$$

The net electric output is the difference in energy between that coming from the thermal convertor minus that sent to the injector. If $80 \%$ of the fusion energy is assumed to be available in the form of energetic neutrons and $20 \%$ is available as charged particles, the net electric output $\left(\mathrm{P}_{\mathrm{NET}}\right)$ can be written as:

$$
P_{N E T}=N_{T}\left((1+0.2 Q) P_{i n j}+0.8 Q M P_{i n j}+P_{i n j}\left(\frac{1-N_{I}}{N_{I}}\right)\right)-\frac{P_{i n j}}{N_{I}}
$$

Similarly, the waste heat $\left(P_{W}\right)$ from the system is $\left(1-N_{T}\right)$ times the inputs to the thermal convertor. $P_{W}$ can be written as:

$$
P_{W}=\left(1-N_{T}\right)\left((1+0.2 Q) P_{i n j}+0.8 Q M P_{i n j}+P_{i n j}\left(\frac{1-N_{I}}{N_{I}}\right)\right)
$$

The system efficiency $\left(\mathrm{N}_{\mathrm{S}}\right)$ is defined as:

$$
\mathrm{N}_{\mathrm{S}}=\frac{{ }_{\mathrm{NET}}}{\mathrm{P}_{\mathrm{NET}}+\mathrm{P}_{W}}
$$

Substitution of C.1 and C.2 into C.3, cancellation of $P_{i n j}$ from all terms and addition of like terms in the denominator result in:

$$
\mathrm{N}_{\mathrm{S}}=\frac{\mathrm{N}_{\mathrm{T}}\left(1+0.2 Q+0.8 Q \mathrm{M}+\left(\frac{1-\mathrm{N}_{I}}{\mathrm{~N}_{\mathrm{I}}}\right)\right)-\frac{1}{\mathrm{~N}_{\mathrm{I}}}}{\left(1+0.2 Q+0.8 Q \mathrm{M}+\left(\frac{1-\mathrm{N}_{\mathrm{I}}}{\mathrm{N}_{\mathrm{I}}}\right)\right)-\frac{1}{\mathrm{~N}_{\mathrm{I}}}}
$$

This equation can also be written as: 


$$
N_{S}=\frac{N_{T}\left(1+0.2 Q+0.8 Q M+\frac{1}{N_{I}}\left(1-N_{I}-\frac{1}{N_{T}}\right)\right)}{1+0.2 Q+0.8 Q M+\frac{T}{N_{I}}\left(1-N_{I}-1\right)}
$$

Collecting like terms results in the expression:

$$
\mathrm{N}_{\mathrm{S}}=\frac{\mathrm{N}_{\mathrm{T}}\left(0.2 \mathrm{Q}+0.8 \mathrm{Q}+\frac{1}{\mathrm{~N}_{\mathrm{I}}}\left(\frac{\mathrm{N}_{\mathrm{T}}-1}{\mathrm{~N}_{\mathrm{T}}}\right)\right)}{0.2 Q+0.8 Q \mathrm{M}}
$$

Finally, this equation can be rearranged to read:

$$
N_{S}=N_{T}\left[1-\frac{1-N_{T}}{Q(0.2+0.8 M) N_{I} N_{T}}\right]
$$

Therefore, the system efficiency $\left(\mathrm{N}_{\mathrm{S}}\right)$ asymptotically approaches the thermal efficiency $\left(N_{T}\right)$. This approach is accentuated by large values of M. The second term in this equation is related to the energy which must be reinjected into the system.

The blanket power $\left(P_{B}\right)$ can be expressed as:

$$
P_{B}=0.8 Q M P_{i n j}
$$

Returning to Equation C.1, this equation can be expanded to read:

$$
\mathrm{P}_{\mathrm{NET}}=\mathrm{N}_{\mathrm{T}} \mathrm{P}_{\text {inj }}\left(1+0.2 \mathrm{Q}+0.8 \mathrm{QM}+\frac{1}{\mathrm{~N}_{\mathrm{I}}}\left(1-\mathrm{N}_{\mathrm{I}}-\frac{1}{\mathrm{~N}_{\mathrm{T}}}\right)\right)
$$

as before. Collecting like terms results in:

$$
\mathrm{P}_{\mathrm{NET}}=\mathrm{N}_{\mathrm{T}} \mathrm{P}_{\text {inj }}\left(0.2 \mathrm{Q}+0.8 Q \mathrm{M}+\frac{1}{\mathrm{~N}_{\mathrm{I}}}\left(\frac{\mathrm{N}_{\mathrm{T}}-1}{\mathrm{~N}_{\mathrm{T}}}\right)\right)
$$

Substituting Equation C.8 into Equation C.10 results in:

$$
P_{\text {NET }}=N_{T} P_{B}\left(\frac{0.20}{0.80 M}+1+\frac{1}{0.80 M N_{I}}\left(\frac{N_{T}-1}{N_{T}}\right)\right)
$$


or:

$$
P_{N E T}=N_{T} P_{B}\left[1+\frac{0.25}{M}-\frac{\left(1-N_{T}\right)}{0.8 M Q N_{I} N_{T}}\right]
$$

Thus, the net electrical power $\left(P_{\mathrm{NET}}\right)$ asymptotically approaches the product of the blanket power $\left(P_{B}\right)$ times the thermal conversion efficiency $\left(\mathrm{N}_{T}\right)$ for large values of $M$. The second term in Equation $C .12$ results from the fusion energy released in helium ions which is not multiplied. The third term in Equation $C .12$ results from the power which is reinjected into the plasma and thus is similar to the second term in Equation C.7.

The blanket power $\left(P_{B}\right)$ can be related to the thermal and physical characteristics of the blanket region by the expression:

$$
P_{B}=\rho_{C} V_{C}+\rho_{L} V_{L}
$$

where $\rho_{c}=$ Power density of the convertor

$$
\begin{aligned}
& \rho_{L}=\text { Power density of the lattice } \\
& V_{c}=\text { Volume of the convertor } \\
& V_{L}=\text { Volume of the lattice }
\end{aligned}
$$

The volume of the convertor and the lattice are calculated from geometric considerations which allow for injector and leakage ports. The size of the leakage ports is fixed by the mirror design. The size of the injector ports is somewhat a function of the injection power but, in this analysis, their size was assumed fixed. The power densities of the convertor and lattice are derived from heat transfer considerations.

For a 320-faced geodesic blanket with a module triangular area of $A_{1}$, the convertor volume can be calculated by:

$$
v_{c}=\left(\left(320 A_{1}\right)-I-L\right) h_{c}
$$

where $h_{c}$ is the height of the convertor, I is the injector port crosssectional area at the vacuum wall and $L$ is the leakage port area at the vacuum wall. The lattice volume can similarly be calculated by: 


$$
V_{L}=\left(\left(320 A_{1}\right)-I-L\right) h_{L}
$$

where $h_{L}$ is the height of the lattice.

Substituting Equations C.14 and C.15 into Equation C.13 results in:

$$
P_{B}=\left(\rho_{C} h_{C}+\rho_{L} h_{L}\right)\left(\left(320 A_{1}\right)-I-L\right)
$$

Equations C.7, C.8 and C.12 constitute the analytical model used in the system design with Equation C.16 being used to calculate blanketdependent parameters. In the analys is reported, $P_{B}$ was calculated from Equation C.16, $M$ derived from previous blanket analysis and $\mathrm{N}_{T}$ selected by thermal hydraulics analysis. Thus, parameters varied in the studies included $N_{S}, Q N_{I}, P_{i n j}$ and $P_{N E T}$. 
BNWL-1835

\section{REFERENCES}

1. R. W. Werner, Lawrence Livermore Laboratory, Private Communication, June 1973. 
BNWL-1835

\section{APPENDIX D}


APPENDIX D

\section{BUCKLING EXPRESSIONS IN CTR GEOMETRY}

During the course of performing preliminary parametric studies on multiplying blankets for fusion reactors, it was found to be convenient to be able to estimate the neutron leakage from the blanket region. This was done by employing the geometric buckling $\left(B^{2}\right)$ concept developed in reactor physics. Because the geometric shapes employed in fusion reactor blankets differ markedly from fission reactor cores, buckling expressions consistent with these geometries were developed. These expressions were used in some of the neutronic parametric studies and their developments are given here.

We will consider the calculation of the steady state neutron equation in an infinite hollow cylinder. The equation for this calculation in a cylinder is written as:

$$
\frac{1}{r} \frac{d}{d r}\left(r \frac{d \phi}{d r}\right)+B^{2} \phi=0
$$

The general solution to Equation D.1 is:

$$
\phi=\mathrm{AJ}_{0}(\mathrm{Br})+\mathrm{Cr}_{0}(\mathrm{Br})
$$

where $S=$ Inner radius of the cylinder

$$
\mathrm{R}=\text { Outer radius of the cylinder }
$$$$
B^{2} \quad=\text { Geometric buckling }
$$

$A$ and $C=$ Coefficients

$$
\begin{array}{ll}
\left.\begin{array}{ll}
J_{0} & = \\
\gamma_{0} & =
\end{array}\right\} \text { Known Bessel function expressions } \\
\phi & =\text { Neutron flux }
\end{array}
$$

The coefficients $A$ and $C$ must now be determined.

The following boundary conditions have been assumed as being most consistent with the problem at hand: 


$$
\begin{aligned}
& \phi(R)=0 \\
& \left.\frac{d \phi}{d r}\right|_{S}=0
\end{aligned}
$$

Differentiating the expression for the neutron flux as a function of the spacial dimension $(r)$ results in the following expression:

$$
\frac{d \phi}{d r}=\frac{A d\left[J_{0}(B r)\right]}{d r}+\frac{C d\left[Y_{0}(B r)\right]}{d r}
$$

Expression D.5 can be written as:

$$
\frac{d \phi}{d r}=-A B J_{1}(B r)-C B \gamma_{1}(B r)
$$

by taking advantage of known Bessel function relationships. By applying the second boundary condition (D.4), Equation D.6 can be written as:

$$
0=\mathrm{Ad}_{1}(\mathrm{Bs})+\mathrm{CY}_{1}(\mathrm{Bs})
$$

Equation D.7 can then be solved for the coefficient A.

$$
A=-\frac{C Y_{1}(B s)}{J_{1}(B s)}
$$

The first boundary condition (D.3) can then be applied to Equation D.2.

$$
0=\mathrm{AJ}_{0}(\mathrm{BR})+\mathrm{CY}_{0}(\mathrm{BR})
$$

Equation $D .9$ can also be solved for the coefficient $A$.

$$
A=-\frac{C Y_{0}(B R)}{J_{0}(B R)}
$$

Expressions D. 8 and $D .10$ can then be equated to form a transcendental solution to the buckling equation for these conditions. This equation is the solution for the buckling of a hollow cylinder for the stated boundary condition.

$$
\frac{Y_{0}(B R)}{J_{0}(B R)}=\frac{Y_{1}(B S)}{J_{1}(B S)}
$$

For mirror reactors, a buckling expression for a hollow sphere has proven to be useful. The solution to the steady state neutron diffusion Equation D.1 for a sphere can be written as: 


$$
\phi(r)=\frac{A \sin B r}{r}+\frac{C \cos B r}{r}
$$

This solution is subject to the following boundary conditions in this instance:

$$
\begin{aligned}
& \phi(R)=0 \\
& \left.\frac{d \phi}{d r}\right|_{S}=0
\end{aligned}
$$

where $R$ is the outer radius of the hollow sphere and $s$ is the inner radius of the hollow sphere.

Applying boundary condition $D .13$ to Equation D.12 results in the expression:

$$
0=\frac{A \sin B R}{R}+\frac{C \cos B R}{R}
$$

Equation D.15 can be solved for the coefficient $A$ by:

$$
A=-\frac{C}{\tan B R}
$$

Then, differentiating the flux solution results in:

$$
\begin{aligned}
\frac{d \phi}{d r} & =\frac{A B r \cos B r-A \sin B r}{r^{2}} \\
& -\frac{C B r \sin B r+C \cos B r}{r^{2}}
\end{aligned}
$$

Collecting like terms changes this expression to:

$$
\frac{d \phi}{d r}=A\left[\frac{B \cos B r}{r}-\frac{\sin B r}{r^{2}}\right]-C\left[\frac{B \sin B r}{r}+\frac{\cos B r}{r^{2}}\right]
$$

Applying boundary condition D.14 to Equation D.17 and solving for the coefficient $A$ results in:

$$
A=\frac{C\left[\frac{B \sin B s}{s}+\frac{\cos B s}{s^{2}}\right]}{\left[\frac{B \cos B s}{s}-\frac{\sin B s}{s^{2}}\right]}
$$

Equations D.16 and D.19 can then be equated. Cancellation of like terms and some manipulation results in: 


$$
\frac{B s \tan B s+1}{B s-\tan B s}=-\frac{1}{\tan B R}
$$

Equation D.20 is a transcendental equation for the geometric buckling of a hollow sphere for the boundary conditions of interest.

In addition to the above expression, it can be shown that the buckling expression for the hollow sphere with boundary corditions $\phi(s)=$ $\phi(R)=0$ is the same as that for a slab of thickness $(R-s)$.

The buckling expressions derived here are summarized in Table D.1.

TABLE D.1 Geometric Buck1ing Expressions for Fusion Reactor Blankets

GEOMETRY BOUNDARY CONDITIONS EQUATION

\begin{tabular}{|c|c|c|}
\hline $\begin{array}{l}\text { INFINITE } \\
\text { HOLLOW } \\
\text { CYLINDER }\end{array}$ & $\begin{array}{l}\text { FLUX }=0 \text { AT OUTER } \\
\text { RADIUS, CURPENT }=0 \\
\text { AT IMIER PADTUS }\end{array}$ & $\frac{Y_{0}(B R)}{J_{0}(B P)}=\frac{Y_{1}(B s)}{J_{1}(B s)}$ \\
\hline $\begin{array}{l}\text { HOLLON } \\
\text { SPHEPE }\end{array}$ & $\begin{array}{l}\text { FLUUX }=0 \text { AT OUTER } \\
\text { PRDIUS, CURRENT = } 0 \\
\text { AT IINER RADIUS }\end{array}$ & $\frac{B s \tan B s \div 1}{B S-\tan B S}=-\frac{1}{\tan B R}$ \\
\hline $\begin{array}{l}\text { HOLLOW } \\
\text { SPHERE }\end{array}$ & $\begin{array}{l}\text { FIUX }=0 \text { AT OUTER } \\
\text { AND INNER RADIUS }\end{array}$ & $B^{2}=\frac{\pi^{2}}{(R-s)^{2}}$ \\
\hline
\end{tabular}

The equations in Table D.1 were solved for B using a digital computer for the spatial dimensions of interest and the results were used in some of the parametric analyses covered in this report. 
No. of

Copies

OFFSITE

A. A. Churm

AEC Patent Group

U.S. Atomic Energy Commission

9800 South Cass Avenue

Argorine, IL 60439

5 L. Bogart

U.S. Atomic Energy Commission

Washington, D.C. 20545

L. Levine

Plasma Physics Division

U.S. Naval Research Laboratory

Washington, D.C. 20390

T. B. Taylor

General Research Corporation

1501 Wilson Boulevard

Arlington, Virginia 22209

W. C. Gough

Electric Power Research Institute 3412 Hillview

Palo Alto, California 94304

Robert Conn

Materials, Nuclear Engineering

Department

University of Wisconsin

Madison, Wisconsin 53706

Gerry Kulcinski

Materials, Nuclear Engineering Department

University of Wisconsin

Madison, Wisconsin 53706

\section{S. Skupsky}

The University of Rochester

Laboratory for Laser Energetics

College of Engineering and Applied Science

River Station

Rochester, New York 14627
No. of

Copies

OFFSITE

Yu. F. Chernilin

Dept. of Technical Operations

International Atomic Energy Agency

P. 0. Box 590, Karntner Ring II

A-1011, Vienna, Austria

Francis Chen

Dept. of Electrical Engineering

University of California

Los Angeles, California 90024

M. Hoffman

University of California

Davis, California 95616

J. Holdren

University of California

Berkeley, California 94720

Dr. George Hopkins

General Atomics

P. 0. Box 81608

San Diego, California 92112

V. Arp

Cryogenics Division

National Bureau of Standards

Boulder, Colorado 80302

Alan Haught

United Aircraft Research Laboratories

United Aircraft Corporation

East Hartford, Connecticut 06108

Paul Persiani

Argonne National Laboratory

9700 South Cass Avenue

Argonne, Illinois 60439 
BNWL-1835

No. of

Copies

OFFSITE

Michael Petrick

Associate Director

Engineering and Technology Div.

Argonne National Laboratory

9700 South Cass Avenue

Argonne, Illinois 60439

C. Hendricks

Dept. of Electrical Engineering

University of Illinois

Urbana, I11inois 61803

G. Miley

214 Nuclear Engineering Laboratory

University of Illinois

Urbana, Illinois 61801

Zeinab Sabri

Nuclear Engineering Department

Iowa State University

Ames, Iowa 50010

L. Lidsky

Dept. of Nuclear Engineering

Massachusetts Institute of Technology

Cambridge, Massachusetts 02139

David Rose

Mechanical Engineering Dept.

Massachusetts Institute of

Technology

Cambridge, Massachusetts 02139

H. Gomberg

KMS Fusion

Ann Arbor, Michigan

Terry Kammash

Nuclear Engineering Department

College of Engineering

University of Michigan

Ann Arbor, Michigan 48105
Ho. of

Copies

OFFSITE

Dr. Abrahamson

School of Public Affairs

Social Science Building, Rm. 309

University of Mirnesota 55455

Charles Halpern

Esso Research and Engineering Co.

P. 0. Box 45

Linden, New Jersey 07036

R. A. Huse

Public Service Electric \& Gas Co. Manager of Research and Development 80 Park Place

Newark, New Jersey 07101

E. F. Johnson

Princeton Plasma Physics Lab.

Princeton University

P. 0. Box 451

Princeton, New Jersey 08540

Robert G. Mills

Princeton University Library

Princeton University

P. 0. Box 451

Princeton, New Jersey 08540

F. Ribe

Los Alamos Scientific Laboratory

Los Alamos, New Mexico 87544

Dr. Glenn Whan

Department of Nuclear Engineering University of New Mexico

Albuquerque, New Mexico 87106

R. A. Gross

Professor of Engineering Science

Plasma Research Laboratory

Columbia University

New York, New York 10027 
BNWL-1835

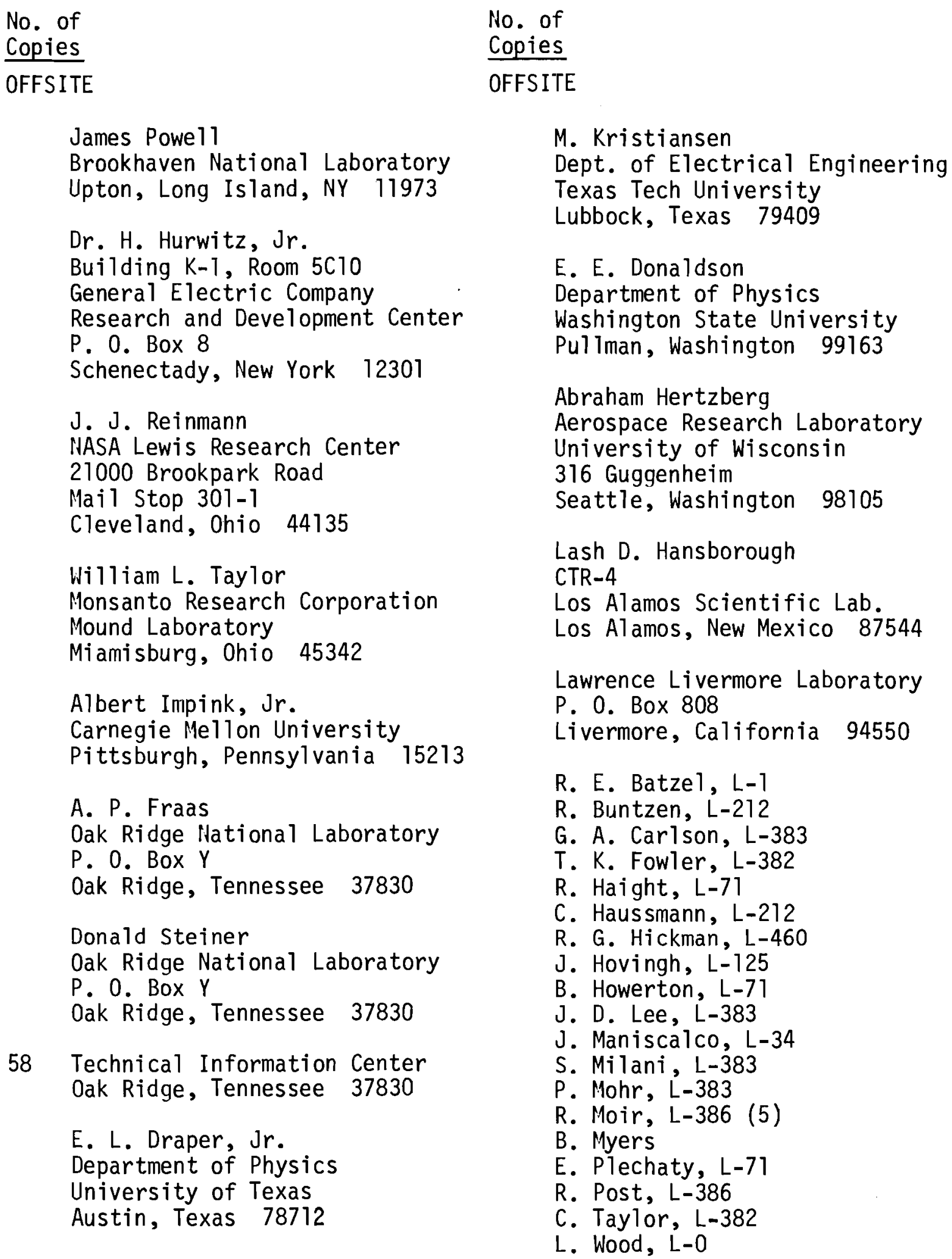


No. of

Copies

ONSITE

Battel1e-Northwest

D. T. Aase

N. E. Carter

J. W. Finnigan

R. H: Fleischman

B. F. Gore

C. M. Heeb

U. P. Jenquin

A. B. Johnson

B. R. Leonard, Jr. (5)

R. C. Liikala

R. P. Marsha11

D. F. Newman

L. T. Pedersen

L. C. Schmid

C. W. Stewart

A. M. Sutey

L. D. Williams

W. C. Wolkenhauer

AEC Richland Operations Office

B. J. Melton 